\title{
Synthesis of Carbon Nanotubes (CNTs) from Poultry Litter for Removal of Chromium (Cr (VI)) from Wastewater
}

\author{
Noor Haleem ${ }^{1,2, * \mathbb{D}}$, Yousuf Jamal ${ }^{1,3} \mathbb{D}$, Shahid Nawaz Khan ${ }^{4} \mathbb{D}$, Muhammad Anwar Baig ${ }^{1}$, Maryam Wahab 5 \\ and Xufei Yang ${ }^{2}$
}

1 Institute of Environmental Sciences and Engineering (IESE), National University of Sciences and Technology (NUST), Islamabad 44000, Pakistan; yousufjamal.icet@pu.edu.pk (Y.J.); ma_baig@lycose.com (M.A.B.)

2 Agriculture and Biosystems Engineering Department, South Dakota State University, Brookings, SD 57007, USA; xufei.yang@sdstate.edu

3 Institute of Chemical Engineering \& Technology (ICET), University of the Punjab, Lahore 54590, Pakistan

4 Institute of Geographical Information Systems (IGIS), National University of Sciences and Technology (NUST), Islamabad 44000, Pakistan; snawaz@igis.nust.edu.pk

5 Atta Ur Rahman School of Applied Biosciences (ASAB), National University of Sciences and Technology, Islamabad 44000, Pakistan; Mwahab.mshcb06asab@nust.edu.pk

* Correspondence: nhaleem@iese.nust.edu.pk

check for updates

Citation: Haleem, N.; Jamal, Y.; Khan, S.N.; Baig, M.A.; Wahab, M.; Yang, X. Synthesis of Carbon Nanotubes (CNTs) from Poultry Litter for Removal of Chromium (Cr (VI)) from Wastewater. Materials 2021, 14, 5195. https://doi.org/10.3390/ ma14185195

Academic Editors: Roberta G. Toro, Farooq Sher and Stefano Bellucci

Received: 9 June 2021

Accepted: 27 August 2021

Published: 10 September 2021

Publisher's Note: MDPI stays neutral with regard to jurisdictional claims in published maps and institutional affiliations.

Copyright: (c) 2021 by the authors. Licensee MDPI, Basel, Switzerland. This article is an open access article distributed under the terms and conditions of the Creative Commons Attribution (CC BY) license (https:/ / creativecommons.org/licenses/by/ $4.0 /)$.
Abstract: Pakistan, an agricultural country, raises 146.5 million commercial and domestic poultry birds, which generate around 544,831 tons of waste per year. This waste finds its final disposal in agricultural land as soil fertilizer or disposal site amendment. The usage of poultry litter for this purpose is uncontrolled, which results in environmental degradation such as emission of greenhouse gases, e.g., methane. However, alternative options such as thermochemical conversion of poultry litter can offer better solutions where this waste can be used as a low-cost carbon source for the synthesis of Multiwalled Carbon Nanotubes (MWCNTs). In this study, efforts were made to utilize this cheap and plentiful carbon source for the synthesis of CNTs in the presence of $\mathrm{Ni} / \mathrm{Mo} / \mathrm{MgO}$ as a catalyst, through pyrolysis. For a better yield of carbon product, the optimum ratio for the catalysts $(\mathrm{Ni} / \mathrm{Mo} / \mathrm{MgO})$ was found to be 4:0.2:1. Furthermore, the process parameters were also optimized for better carbon yield. A good yield of CNTs resulted from a pyrolysis time of $12 \mathrm{~min}$, a temperature of $825^{\circ} \mathrm{C}$, and a catalyst weight of $100 \mathrm{mg}$. The structure and morphology of the produced nanotubes were confirmed through X-ray Diffractometer (X-RD) and Scanning Electron Microscopy (SEM). The environmental application of the nanotubes was tested in a synthetic chromium solution in the lab using a batch experiment. Different experimental conditions $(\mathrm{pH}$, adsorbent dosage, and contact time) were optimized to improve the adsorption of $\mathrm{Cr}$ (VI) by carbon nanotubes and a UV-Visible spectrophotometer was used at $540 \mathrm{~nm}$ to measure the absorbance of $\mathrm{Cr}(\mathrm{VI})$. The results showed that up to $81.83 \%$ of $\mathrm{Cr}(\mathrm{VI})$ removal was achieved by using $8 \mathrm{mg}$ of CNTs at $\mathrm{pH} 3$ with $400 \mathrm{rpm}$ at $180 \mathrm{~min}$ of contact time. Thus, it was concluded that poultry litter can be a useful source for the synthesis of MWCNTs and thereby removal of Cr (VI) from industrial tanneries' wastewater.

Keywords: poultry litter; carbon nanotubes; catalyst; experimental conditions; adsorption

\section{Introduction}

In Pakistan, the poultry sector is one of the vibrant segments of the livestock division. According to 2016-2017 statistics, 85.86 million domestic poultry and 60.6 million commercial poultry were produced [1]. In Pakistan, the poultry industry has a vital status in the rural economy considered the second largest industry and an income source for millions of people. [2]. Asia is the top regional exporter of prepared chicken products, delivering more than 800,000 tons in 2014, while Europe is the main buyer, purchasing more than one million tons in that year [3]. Organic waste from poultry is mainly the litter, which consists of several elements such as chicken urine and feces. However, there is also a mixture of 
several items such feed sawdust and bedding materials such as wood shavings in poultry litter. The quality and composition of litter varies with different elements such as diet, dietary supplements, storage of litter, and management practices of the poultry farm [4]. In the literature, quantified data about poultry litter produced in a 42 day cycle fluctuate between 1.5 and $5.7 \mathrm{~kg}$ per bird [5]. The average poultry litter production is $3.72 \mathrm{~kg} / \mathrm{bird}$. Common poultry litter for chicken is normally used several times, which helps to reduce the volume of generating beds [3]. Poultry litter generated by a single broiler unit usually varies due to several parameters such as feed intake by chickens, management scenarios (bedding material), and feed digestibility [6].

For centuries, poultry litter has been used as a fertilizer due to its organic properties for plant growth; it is rich with several nutrients which are required for plants [7]. Macronutrients such as nitrogen, phosphorus, and potassium (NPK) and micronutrients that are required in little amounts for crop growth such as copper, zinc, etc., are present in litter produced by poultry [8]. Poultry litter has been also used as a mulching material, since poultry litter has properties of conservation of soil moisture. During summer when it is hot, it also protects the surface, which feeds the roots [9]. It is also used as a low-cost renewable resource for producing activated carbon by burning the litter to at least $700{ }^{\circ} \mathrm{C}$ resulting in the formation of a lattice-like carbon particle structure. Activated carbon is used for the adsorption of contaminants in wastewater $[10,11]$. Along with this, several physicochemical and hydroponic techniques have been reported for metals removal [12-14].

Transition metals reinforced on silica, mesoporous silica, calcium carbonate, zeolites, or magnesium oxide are used as catalysts for the growth of MWCNTs [15]. Many catalysts have been studied to improve and change the structure and properties of MWCNTs to increase their yield. Various catalysts, i.e., $\mathrm{Ni}, \mathrm{Co}, \mathrm{Mo}$, and $\mathrm{Fe}$ have been used for the growth of MWCNTs. Supported metal catalysts have been formed by using the impregnation method. Keeping in view all parameters related to the chemistry of metal is important while performing the impregnation method for manufacturing a supported metal catalyst [16].

Nanomaterials are progressively used for diverse modern technologies and CNTs are among the most prominent. MWCNTs are made of graphene sheets of a hexagonal structure rolled up into a nanoscale tube. They vary in their lengths up to a million times as compared to their diameter, which is up to $0.4 \mathrm{~nm}$ [17].

MWCNT synthesis and its utilization have been studied across the world in the last few years with extraordinary attention. Today, MWCNTs and their use in different areas are discussed widely in scientific circles. Usage of MWCNTs for removal of different wastes such as organic waste, inorganic waste, and radionuclides from wastewater is very common. Several researchers reported the extensive applications of these materials in a variety of areas such as science, engineering, energy storage, electrochemical super capacitors, etc. MWCNTs have exceptional properties in terms of physical, electrical, and mechanical aspects and thus have encouraged new technologies. Other factors that make them different from other materials are their density (nearly half the density of aluminum), stiffness, and large surface area [18].

The hydrocarbon sources used for the growth of MWCNTs include mainly ethylene, methane, and acetylene. Liquid hydrocarbons such as benzene, xylene, cyclohexane, and alcohol are also being used as CNTs precursors. Carbon nanotubes can also be generated from solid biomass waste such as rice straw [19] and propylene bottles [20].

Research on the direct growth of MWCNTs has been reported using in situ techniques in which a catalyst, i.e., transition metal alloy is taken and a carbon containing material is passed through it. However, the only challenge is that catalyst creation is very lengthy, tiresome, and too costly, which may increase the cost of the MWCNTs. Recently, magnetic separation techniques have increasingly come to the attention of scientists [21]. The applications can be seen in many fields such as medicine, cell biology, analytical chemistry, and environmental engineering. The synthesized magnetic MWCNTs can be well dispersed in water. Moreover, the removal of MWCNTs, from a medium with the help of a magnet 
is convenient [22]. Removal of heavy metals, organic, and inorganic contaminants using biochar [23] and magnetic CNTs [24] as adsorbents has been reported.

There are two objectives for this study. First, poultry litter as a carbon source is used to produce MWCNTs with a Ni/Mo/MgO catalyst. Response Surface Methodology (RSM) was used to optimize the parameters (such as temperature, time, and weight of the catalyst) both for catalyst preparation and growth of MWCNTs. The second objective of this research was to analyze the adsorption behavior of CNTs for $\mathrm{Cr}$ (VI) adsorption. Effects of factors, such as system $\mathrm{pH}$, adsorbent dosage, and adsorbent contact time were investigated. $\mathrm{pH}$ effects on the removal of $\mathrm{Cr}(\mathrm{VI})$ were also investigated.

\section{Materials and Method}

Commercial poultry units in Islamabad, Pakistan were reached for the collection of poultry litter. Fresh litter was collected since the flock was just removed from the poultry farms. Litter was then transported to the Institute of Environmental Sciences and Engineering (IESE). The bedding material was constituted of sawdust, no medicine was given to the birds during the growth phase. The initial poultry litter sample of $3 \mathrm{~kg}$ was kept in closed bags. For the synthesis of the catalyst, Nickel Nitrate hexahydrate $\left(\mathrm{Ni}\left(\mathrm{NO}_{3}\right)_{2} \cdot 6 \mathrm{H}_{2} \mathrm{O}\right)$, Ammonium Molybdate tetrahydrate $\left.\left(\mathrm{NH}_{4}\right)_{6} \mathrm{Mo}_{7} \mathrm{O}_{24} \cdot 4 \mathrm{H}_{2} \mathrm{O}\right)$, Magnesium nitrate hexahydrate $\left(\mathrm{Mg}\left(\mathrm{NO}_{3}\right)_{2} \cdot 6 \mathrm{H}_{2} \mathrm{O}\right)$, Citric acid, Hydrochloric Acid $(\mathrm{HCl})$, Sodium Hydroxide $(\mathrm{NaOH})$, and Ethanol were purchased from Sigma Aldrich, St. Louis, MO, USA. The chemicals used in this study were of analytical grade and were used in the form they were received. In all the experimental runs, distilled water was used.

\subsection{Synthesis of Catalyst}

The wet impregnation method was used for the synthesis of catalysts. The solution of $116.28 \mathrm{~g}$ of $\mathrm{Ni}\left(\mathrm{NO}_{3}\right)_{2} \cdot 6 \mathrm{H}_{2} \mathrm{O}, 24.71 \mathrm{~g}$ of $\left(\mathrm{NH}_{4}\right)_{6} \mathrm{Mo}_{7} \mathrm{O}_{24} \cdot 4 \mathrm{H}_{2} \mathrm{O}$, and $25.64 \mathrm{~g}$ of $\mathrm{Mg}\left(\mathrm{NO}_{3}\right)_{2}$ $6 \mathrm{H} 2 \mathrm{O}$ was added to $200 \mathrm{~mL}$ of distilled water and stirred for $1 \mathrm{~h}$ on a magnetic hot plate. The mixture was heated to $90^{\circ} \mathrm{C}$ up to $1 \mathrm{~h}$ after the addition of two grams of anhydrous citric acid. The resultant mixture was left on a hot plate for evaporation. The viscous slurry was oven-dried at $120^{\circ} \mathrm{C}$ for $12 \mathrm{~h}$. The material was ground into fine powder form and calcinated in the furnace of a tube-like structure at $600^{\circ} \mathrm{C}$ for $2 \mathrm{~h}\left(10^{\circ}\right.$ rise $\left./ \mathrm{min}\right)$ [25].

\subsection{Synthesis of CNTs}

The raw material used for the synthesis of CNTs was poultry litter. The litter was dried in the oven at $120^{\circ} \mathrm{C}$ for $3 \mathrm{~h}$ and ground. Four grams of poultry litter was then mixed manually with $2-8 \mathrm{mg}$ of the catalyst. The mixture was then placed in a porcelain boat (volume $80 \mathrm{~mL}$ ) and combusted using an electrical furnace at $700-950{ }^{\circ} \mathrm{C}$ in a continuous flow of helium gas to provide an inert atmosphere. The porcelain boats were removed after 12 min from the tube furnace. During the decomposition of organic compounds, carbon molecules are deposited on the nickel catalysts placed on magnesium oxide as supporting material. In the reported literature, the synthesis is carried out within the temperature range of $750-850{ }^{\circ} \mathrm{C}[26]$.

\subsection{Process Parameter Optimization with Response Surface Methodology}

The Response Surface Methodology (RSM) with Box-Behnken design was used to maximize the yield of CNTs by optimization of process parameters. In contrast to conventional methods, the interaction between the processes' variables was determined by statistical analysis of the response surface methodology. To optimize the MWCNTs' synthesis, a two level half factorial design with three central points was preferred. The parameters optimized for this study were (a) Reaction Time, (b) Temperature, and (c) Catalyst concentration. For synthesis of the CNT samples, 15 experimental runs were automatically defined by the statistical software. For finding the optimum conditions for the reaction, the response from each experimental run was statistically analyzed based on yield [27]. 


\subsection{Purification of MWCNTs}

Impurities such as residual catalyst and amorphous carbon must be removed from CNTs. This requires chemical and thermal treatment. Catalyst particles were removed by an ultrasonication process in which $37 \%$ concentrated hydrochloric acid was used and stirred for $2 \mathrm{~h}$ on a magnetic hot plate. The resultant mixture was filtered by vacuum after dilution with deionized water. Distilled water was used to neutralize the $\mathrm{pH}$ of the solid carbon product. Oxidation of MWCNTs was performed in a tube furnace at a temperature of $400{ }^{\circ} \mathrm{C}$ for a duration of $2 \mathrm{~h}$, following the method explained by Vivekchand et al. [28].

\subsection{Functionalization of $C N T$}

A solution of $200 \mathrm{~mL}$ of $6.0 \mathrm{M} \mathrm{HNO}_{3}(70 \%)$ was prepared and $0.7 \mathrm{~g}$ MWCNT was spread in this solution by the dispersion method. An ultrasound bath was used for $20 \mathrm{~min}$ to maintain the dispersion process. The dispersion was magnetically stirred for $12 \mathrm{~h}$. This period was under nitric acid reflux and under different temperatures ranges of 50, 70, 90, and $110^{\circ} \mathrm{C}$. The dispersion was cooled down at room temperature after removing it from the hot plate after $12 \mathrm{~h}$ of treatment. Centrifugation of the dispersion was performed for $10 \mathrm{~min}$ at $4000 \mathrm{rpm}$. This process separated the supernatant from the mixture by sediment solid residues. The supernatant was filtered under vacuum by using a $0.2 \mu \mathrm{m}$ acetate membrane filter. Distilled water was used to wash the solid residue to remove extra nitric acid from the sample. This washing process continued until the $\mathrm{pH}$ of the filtrate became neutral. Finally, the MWCNTs were dried for further analysis [29].

\subsection{Adsorption of $\mathrm{Cr}(\mathrm{VI})$}

In $100 \mathrm{~mL}$ distilled water, $0.2829 \mathrm{~g}$ of potassium dichromate (K2Cr2O7) was dissolved, and the $\mathrm{Cr}(\mathrm{VI})$ stock solution of $1000 \mathrm{mg} \mathrm{L}^{-1}$ was produced. To prepare various solutions of different concentrations of $\mathrm{Cr}(\mathrm{VI})$, the stock solution was diluted with distilled water. Adsorption analyses were conducted by blending 2, 4, 6, and $8 \mathrm{mg}$ of MWCNTs with $50 \mathrm{~mL}$ $\mathrm{Cr}$ (VI) solutions of $100 \mathrm{ppm}$ in a $100 \mathrm{~mL}$ volumetric flask. The solutions were agitated at $500 \mathrm{rpm}$ over various contact times from $30 \mathrm{~min}$ to $210 \mathrm{~min}$ with an increment of $30 \mathrm{~min}$. $\mathrm{Cr}$ (VI) solution $\mathrm{pH}$ values were tweaked to $2.0-7.0$ by using $1.0 \mathrm{M} \mathrm{HCl}$ and $1.0 \mathrm{M} \mathrm{NaOH}$ solution [30].

The effect of the adsorbent dosage was determined, and a $\mathrm{pH}$ value of 3 and the initial $\mathrm{Cr}$ (VI) concentrations in the solutions were used. An acetate membrane filter of $0.2 \mu \mathrm{m}$ thickness was selected to separate the aqueous phase. A UV-Visible spectrophotometer was used to detect the absorbance of $\mathrm{Cr}(\mathrm{VI})$.

\subsection{Characterizations}

\subsubsection{X-ray Diffraction}

To obtain the pattern of X-ray diffraction of the catalyst, an X-ray diffractometer (Theta/Theta STOE Jeol, Freising, Germany) was used. The samples were prepared by pressing the powders between two glass slides into a flattened sheet. The radiation source $\mathrm{CuK}$ was used for taking X-ray patterns and $40 \mathrm{kV}$ and $40 \mathrm{~mA}$ was supplied to the X-ray generator. The patterns were recorded at $2 \theta$ from $20^{\circ}$ to $70^{\circ}$.

\subsubsection{Scanning Electron Microscopy (SEM)}

SEM (Jeol JSM-6490A, Tokyo, Japan Analytical scanning electron microscope) was used in this study to analyze the surface morphologies of the samples. The samples were coated with a thin layer of the conducted material (gold). They were then imaged at $\times 20,000, \times 35,000$, and 75,000 magnifications, the accelerating voltage was $10-15 \mathrm{kV}$. A focused high beam of electrons interacted with the surface of the sample and generated secondary electron, backscattered electron, and characteristic X-ray signals. The detector processed the signals and displayed the images on a screen [31]. 


\subsubsection{Transmission Electron Microscopy (TEM)}

The sample was characterized using a Jeol JEM-100cx transmission electron microscope. An accelerating voltage of $20 \mathrm{kV}$ was used for characterization. The prepared sample was first sonicated in ethanol for $5 \mathrm{~min}$ at room temperature, and then a drop of dispersion was deposited on a $\mathrm{Cu} / \mathrm{Rh}$ grid covered with a vinyl polymer (formvar), and the grid was dried overnight under vacuum [32].

\subsubsection{Raman Spectroscopy}

Raman spectroscopy of the synthesized CNTs was performed using a Raman Spectrophotometer uRaman-532 TEC-Ci Technospex, Bukit Merah, Singapore, in ambient conditions. The spectrum was recorded using an incident laser with an excitation wavelength of $532 \mathrm{~nm}$, and the samples were exposed for $60 \mathrm{~s}$.

\section{Results and Discussion}

\subsection{Initial Analysis of Poultry Litter}

\subsubsection{Moisture Content}

The moisture content $(w / w \%)$ of the poultry litter (PL) was determined as the weight loss of about $91.87 \mathrm{~g}$ of the sample when dried in an oven at $105^{\circ} \mathrm{C}$ for $8 \mathrm{~h}$. The total moisture content of raw material was $54.06 \%$ as illustrated in Table 1.

Table 1. Moisture content of poultry litter.

\begin{tabular}{|c|c|c|c|}
\hline Sr. No & $\begin{array}{l}\text { Weight of PL before Drying (W2) } \\
\text { (gm) }\end{array}$ & $\begin{array}{c}\text { Weight of PL after Drying (W1) } \\
\text { (gm) }\end{array}$ & $\begin{array}{c}\text { Moisture Content } \\
(\%)\end{array}$ \\
\hline 1. & 200 & 89.64 & 55.18 \\
\hline 2. & 200 & 82.28 & 58.88 \\
\hline \multirow[t]{2}{*}{3.} & 200 & 103.7 & 48.5 \\
\hline & & $\begin{array}{l}\text { Mean }=91.87 \\
\text { S.D }=10.88\end{array}$ & $\begin{array}{c}\text { Mean }=54.18 \\
\text { S.D }=5.26\end{array}$ \\
\hline
\end{tabular}

Average of the above dry weight $=91.87$. Putting this into Equation (1)

$$
\mathrm{M}=\frac{200-91.87}{200} \times 100=54.06 \%
$$

\subsubsection{Elemental Analysis}

The spectroscopic method (Section 3.7.3) was used to determine the elemental concentrations in the poultry litter as depicted in Figure 1. Analysis of the surface composition of the poultry litter is illustrated in Table 2. Concentrations of $\mathrm{C}, \mathrm{N}, \mathrm{P}, \mathrm{O}, \mathrm{CI}, \mathrm{Na}, \mathrm{Ca}, \mathrm{Mg}$, $\mathrm{S}$, and $\mathrm{Si}$ were found in PL samples without bedding material (not mixed with bedding material).

Table 2. Elemental analysis of poultry litter.

\begin{tabular}{ccccccccccc}
\hline Elements & $\mathbf{C}$ & $\mathbf{N}$ & $\mathbf{O}$ & $\mathbf{N a}$ & $\mathbf{M g}$ & $\mathbf{S i}$ & $\mathbf{S}$ & $\mathbf{C l}$ & $\mathbf{K}$ & $\mathbf{C a}$ \\
\hline Conc. & 65.17 & 1.55 & 18.77 & 0.70 & 0.50 & 0.04 & 0.08 & 0.72 & 1.71 & 0.98 \\
\hline
\end{tabular}




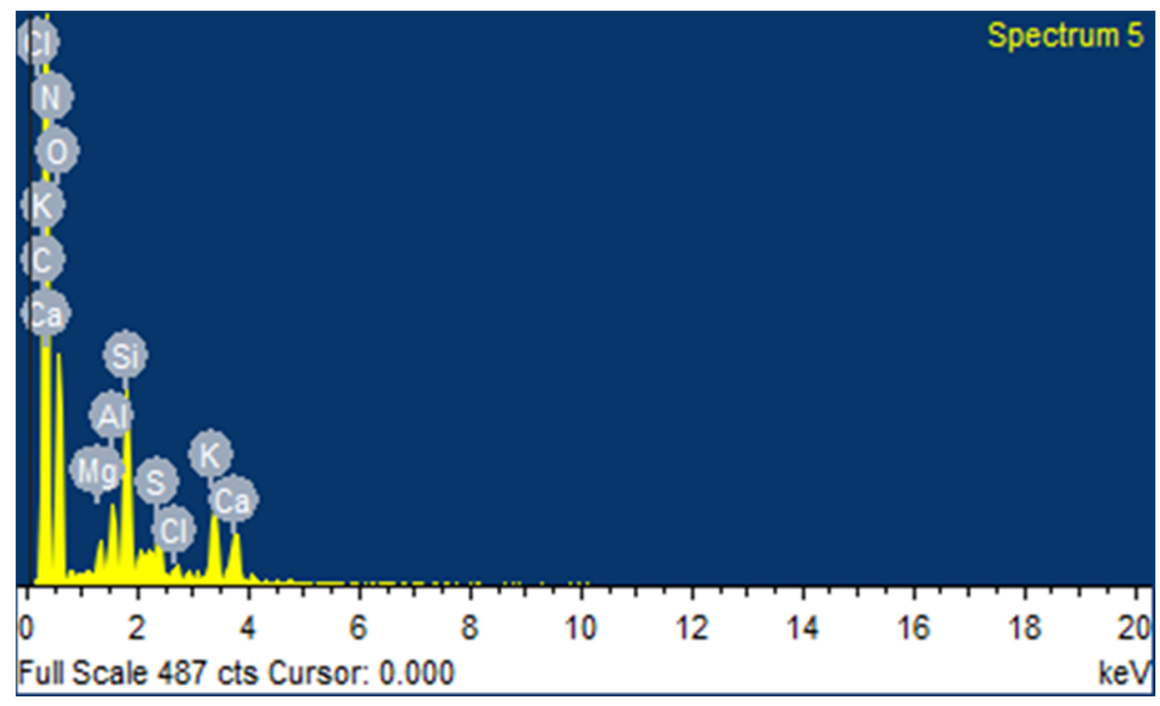

Figure 1. EDS of poultry litter through SEM.

\subsection{Optimization of Mole Ratio of Catalyst Precursors}

To characterize the effects of the Ni/Mo mole ratio on the carbon yield RSM was applied. The outcome of each independent variable ( $\mathrm{Ni} / \mathrm{Mo} / \mathrm{MgO}$ mole ratio) on the dependent variable (carbon yield) was subjected to linear regression. Multiple linear regression was used to explain the association between one continuous dependent variable (carbon yield \%) and three independent variables (concentration of $\mathrm{Ni}, \mathrm{Mo}$, and $\mathrm{MgO}$ ). To confirm the effects of the catalyst on the carbon yield, various concentrations of $\mathrm{Ni}$, $\mathrm{Mo}$, and $\mathrm{MgO}$ were studied as shown in Table 3. For optimization of a process parameter, 15 trial runs were executed. The data in Table 3 show that $\mathrm{Mo}, \mathrm{MgO}$, and Ni contents varied from 0.2 to $0.6,1.0$ to 3.0 , and 2.0 to 6.0 moles, respectively. With the increase in $\mathrm{Ni}$ concentration up to 4 moles, the carbon yield experienced a sharp increase. Further increase in $\mathrm{Ni}$ did not lead to further increase in carbon yield; rather, it tended to decrease with a further increase in Ni. This sudden decrease indicated that Mo and Ni should be in a suitable ratio for optimized carbon yield. It was also observed that for an increased yield of carbon more moles of Ni are required than Mo. Secondly, CNT growth has not been observed on Mo and was only detected on Ni metal ions, which means Mo solely enhances Ni ions' activity. This shows that for the carbon product formation only a small quantity of $\mathrm{Mo}$ is required. In this study, four moles of $\mathrm{Ni}$ in the catalyst (Ni4Mo0.2MgO1) provided the maximum yield of carbon. Variations in carbon yield could be attributed to the catalysts having the same $\mathrm{Ni} / \mathrm{Mo}$ mole ratio and different $\mathrm{MgO}$ concentrations. This also illustrates another point: an increased quantity of $\mathrm{MgO}$ did not lead to an increase in carbon yield. This is due to the fact that $\mathrm{MgO}$ only provides support for $\mathrm{Mo}$ and $\mathrm{Ni}$ ions.

Table 4 explains the variations in carbon yield due to the change in the $\mathrm{Ni} / \mathrm{Mo}$ mole ratio because of the analysis of variance (ANOVA). It was observed that the suitable model to analyze the response of carbon yield was the quadratic model. From the $p$-value, Fvalue, and coefficient of determination $\left(R^{2}\right)$ of the model, the suitability of the model was established. The importance of the coefficient is determined by the value of $p$, which means the smaller the $p$-value the more important the coefficient is. In this model, an F-value of 117.97 and $p<0.0001$ confirmed the significance of the model. $R^{2}=0.9953$ suggested the fitness of the quadratic model $[27,33]$.

$$
\begin{aligned}
\text { Carbon Yield }=- & -3.60000+23.45066 \mathrm{Ni}+0.328947 \mathrm{Mo}-7.59868 \mathrm{Mg}-0.947368 \mathrm{Ni} * \mathrm{Mo}-0.288158 \mathrm{Ni} \text { * } \\
& \mathrm{Mg}-4.39474 \mathrm{Mo} * \mathrm{Mg}-2.42368 \mathrm{Ni}^{2}+0.065789 \mathrm{Mo}^{2}+2.30526 \mathrm{Mg}^{2}
\end{aligned}
$$


Equation (1) with regard to actual factors was utilized to predict the response for different levels of each factor as shown in Figure 2. Figure 3 illustrates the 3D response of the catalytic activity of $\mathrm{Ni}, \mathrm{Mo}$, and $\mathrm{MgO}$ on the yield of carbon product.

Table 3. Optimization of $\mathrm{Ni} / \mathrm{Mo} / \mathrm{MgO}$ concentrations in the catalyst.

\begin{tabular}{ccccc}
\hline Run & $\begin{array}{c}\text { A: Nickel } \\
(\mathbf{M o l})\end{array}$ & $\begin{array}{c}\text { B: Molybdenum } \\
(\mathbf{M o l})\end{array}$ & $\begin{array}{c}\text { C: Magnesium Oxide } \\
\text { (Mol) }\end{array}$ & $\begin{array}{c}\text { Carbon Yield } \\
(\mathbf{\%})\end{array}$ \\
\hline 1. & 2.00 & 0.20 & 2.00 & 24 \\
2. & 2.00 & 0.40 & 2.00 & 21 \\
3. & 2.00 & 0.60 & 2.00 & 24 \\
4. & 2.00 & 0.40 & 1.00 & 25 \\
\hline 5. & 4.00 & 0.40 & 2.00 & 39 \\
6. & 4.00 & 0.60 & 1.00 & 40 \\
7. & 4.00 & 0.20 & 3.00 & 43 \\
8. & 4.00 & 0.40 & 2.00 & 38 \\
9. & 4.00 & 0.40 & 2.00 & 38 \\
10. & 4.00 & 0.60 & 3.00 & 35 \\
11. & 4.00 & 0.20 & 1.00 & 44 \\
\hline 12. & 6.00 & 0.20 & 2.00 & 37 \\
13. & 6.00 & 0.60 & 2.00 & 32 \\
14. & 6.00 & 0.60 & 3.00 & 39 \\
15. & 6.00 & 0.40 & 1.00 & \\
\hline
\end{tabular}

Table 4. ANOVA for Box-Behnken design for change in carbon yield due to different mole ratios of the catalyst precursors.

\begin{tabular}{ccccccc}
\hline Source & Sum of Squares & df & Mean Square & F-Value & $p$-Value & Significance \\
\hline Model & 763.34 & 9 & 84.82 & 117.97 & $<0.0001$ & significant \\
\hline A-Ni & 277.32 & 1 & 277.32 & 385.72 & $<0.0001$ & - \\
\hline B-Mo & 49.16 & 1 & 49.16 & 68.38 & 0.0004 & - \\
\hline C-Mg & 11.93 & 1 & 11.93 & 16.59 & 0.0096 & - \\
\hline $\mathrm{AB}$ & 0.6131 & 1 & 0.6131 & 0.8528 & 0.3981 & - \\
\hline $\mathrm{AC}$ & 1.08 & 1 & 1.08 & 1.51 & 0.2743 & - \\
\hline $\mathrm{BC}$ & 3.30 & 1 & 3.30 & 4.59 & 0.0851 & - \\
\hline $\mathrm{A}^{2}$ & 335.36 & 1 & 335.36 & 466.45 & $<0.0001$ & - \\
\hline $\mathrm{B}^{2}$ & 0.0000 & 1 & 0.0000 & 0.0000 & 0.9959 & - \\
\hline $\mathrm{C}^{2}$ & 18.96 & 1 & 18.96 & 26.37 & 0.0037 & - \\
\hline Residual & 3.59 & 5 & 0.7189 & - & - & - \\
\hline Lack of Fit & 2.93 & 3 & 0.9760 & 2.93 & 0.2649 & not \\
\hline Pure Error & 0.6667 & 2 & 0.3333 & - & - & - \\
\hline Cor Total & 766.93 & 14 & - & - & - & - \\
\hline
\end{tabular}

$\mathrm{R}^{2}=0.9953 ;$ Adjusted $\mathrm{R}^{2}=0.9869$; Predicted $\mathrm{R}^{2}=0.9287$. 


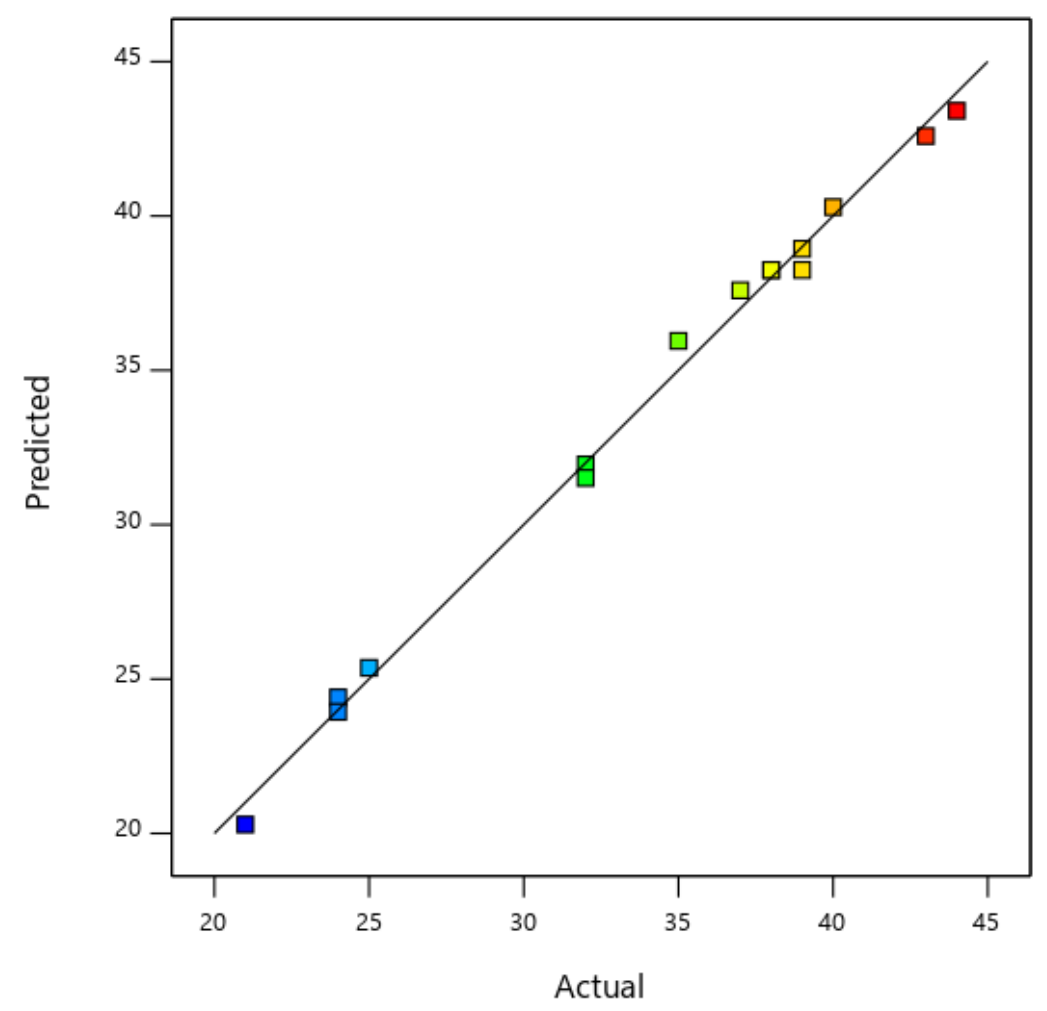

Figure 2. Carbon product predicted and actual yield derived from the RSM model.

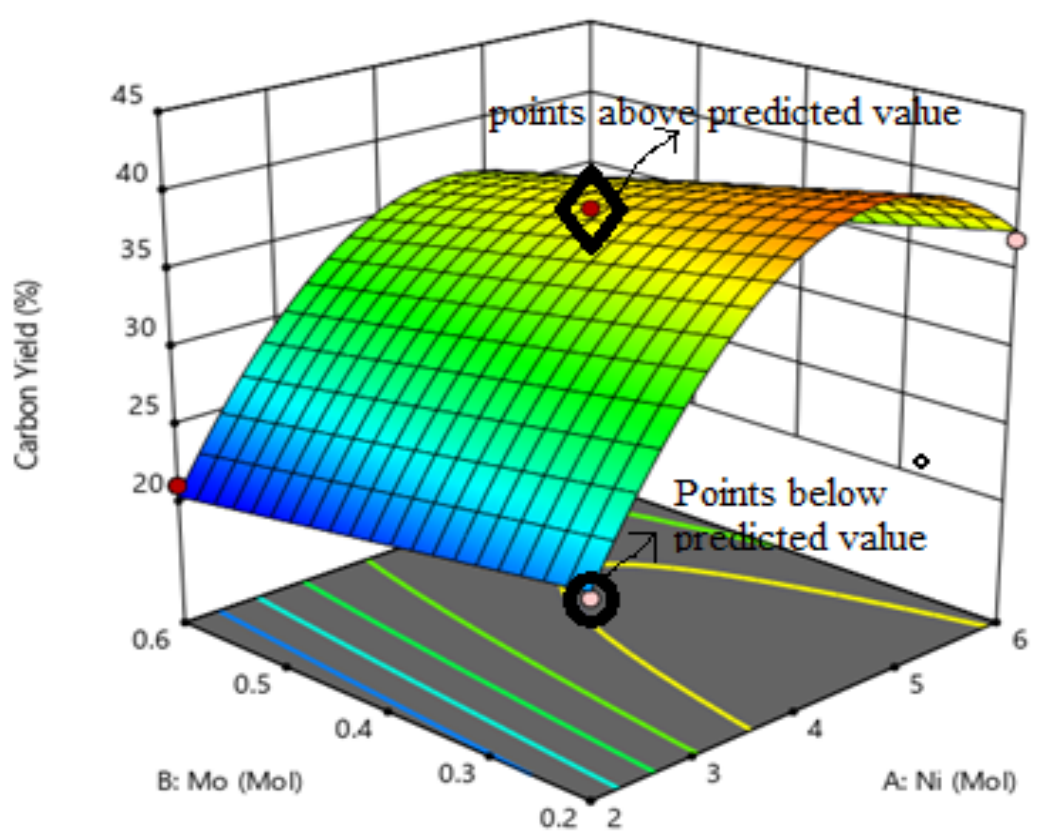

Figure 3. Plot showing catalytic activity of $\mathrm{Ni}, \mathrm{Mo}$, and $\mathrm{MgO}$ over the carbon yield.

\subsection{Statistical Analysis and Modeling for CNTs Growth}

For process parameters, the detection of the initial level is important to carry out. Therefore, optimization was performed using trial experiments. To optimize the process parameters, a full factorial design method and several runs were required. In this research, we executed various experimental runs and their analysis based on results described by [34]. In all the experimental runs, it was observed that less than $12 \mathrm{~min}$ of pyrolysis time led to the partial combustion of poultry waste while more than $20 \mathrm{~min}$ led to the fast oxidation of CNTs as shown in Table 5. CNT growth was not seen below $700{ }^{\circ} \mathrm{C}$ while quick combustion 
of raw material along with CNT oxidation was noted at above $900{ }^{\circ} \mathrm{C}$. The lowest and highest values for poultry waste and catalyst weight were selected based on the porcelain boat's volume employed in the experiments carried out in this study.

Table 5. Process Parameters optimization for CNT growth.

\begin{tabular}{ccccc}
\hline Run & $\begin{array}{c}\text { A: Temperature } \\
\left({ }^{\circ} \mathbf{C}\right)\end{array}$ & $\begin{array}{c}\text { B: Time } \\
(\mathbf{m i n})\end{array}$ & $\begin{array}{c}\text { C: Catalyst Weight } \\
(\mathbf{m g})\end{array}$ & $\begin{array}{c}\text { D: Carbon Yield } \\
\mathbf{( \% )}\end{array}$ \\
\hline 1. & 700.00 & 12.50 & 80.00 & 13.24 \\
2. & 700.00 & 12.50 & 120.00 & 13.85 \\
3. & 700.00 & 5.00 & 100.00 & 14.12 \\
4. & 700.00 & 20.00 & 100.00 & 15.51 \\
\hline 5. & 825.00 & 20.00 & 80.00 & 30.37 \\
6. & 825.00 & 5.00 & 80.00 & 30.86 \\
7. & 825.00 & 20.00 & 120.00 & 31.02 \\
8. & 825.00 & 5.00 & 120.00 & 32.1 \\
9. & 825.00 & 12.50 & 100.00 & 44.04 \\
10. & 825.00 & 12.50 & 100.00 & 44.38 \\
11. & 825.00 & 12.50 & 100.00 & 44.41 \\
\hline 12. & 950.00 & 20.00 & 100.00 & 16.7 \\
13. & 950.00 & 12.50 & 80.00 & 16.72 \\
14. & 950.00 & 12.50 & 120.00 & 17.12 \\
15. & 950.00 & 5.00 & 100.00 & 18.32 \\
\hline
\end{tabular}

Response optimization is influenced by various parameters, a response surface methodology (RSM) was used. Three different levels with the three variable experimental design of Box-Behnken were chosen. Fifteen experimental runs were performed to analyze the influence of the different variables on carbon yield. The correlation between the experimental and predicted yield of carbon product over different variables is shown in Figure 4. Reaction temperature $\left(700-950{ }^{\circ} \mathrm{C}\right)$, poultry litter weight $(2-4 \mathrm{~g})$, catalyst weight $(80-120 \mathrm{mg})$, and reaction time (5-20 $\mathrm{min})$ were chosen to optimize the maximum yield of the carbon product. The optimized values for the synthesis of catalyst $(\mathrm{Ni} / \mathrm{Mo} / \mathrm{MgO})$ with moles of $\mathrm{Ni}, \mathrm{Mo}$, and $\mathrm{MgO}$ for the growth of CNTs were 4:0.2:1. Such a result is consistent with Run 11 in Table 3, with the highest yield ratio of $44 \%$. In the synthesis process of $\mathrm{CNTs}$, carbon diffusion occurs with $\mathrm{Ni}$ and Mo nanoparticles. Moreover, Mo converts to Mo carbide. As the intensity of carbon diffusion on Ni and Mo nanoparticles increases, the carbon precipitation occurs on the Ni-Mo crystal plane and carbon nanotube bundles are produced.

Three-dimensional responses showing the effect of variables on the carbon yield are shown in Figure 5. Table 6 depicts the effects of independent variables (various process parameters) on the dependent variable (carbon yield). The regression equation for the same is illustrated in Equation (4).

Carbon Yield $=-1129.58015+2.34585$ Temperature +3.45479 Time +3.57753 Catalyst Weight -0.000803 Temperature * Time -0.000021 Temperature * Catalyst Weight -0.000983 Time * Catalyst Weight -0.001407 Temperature $^{2}-0.108970$ Time $^{2}-0.017649$ Catalyst Weight ${ }^{2}$ 


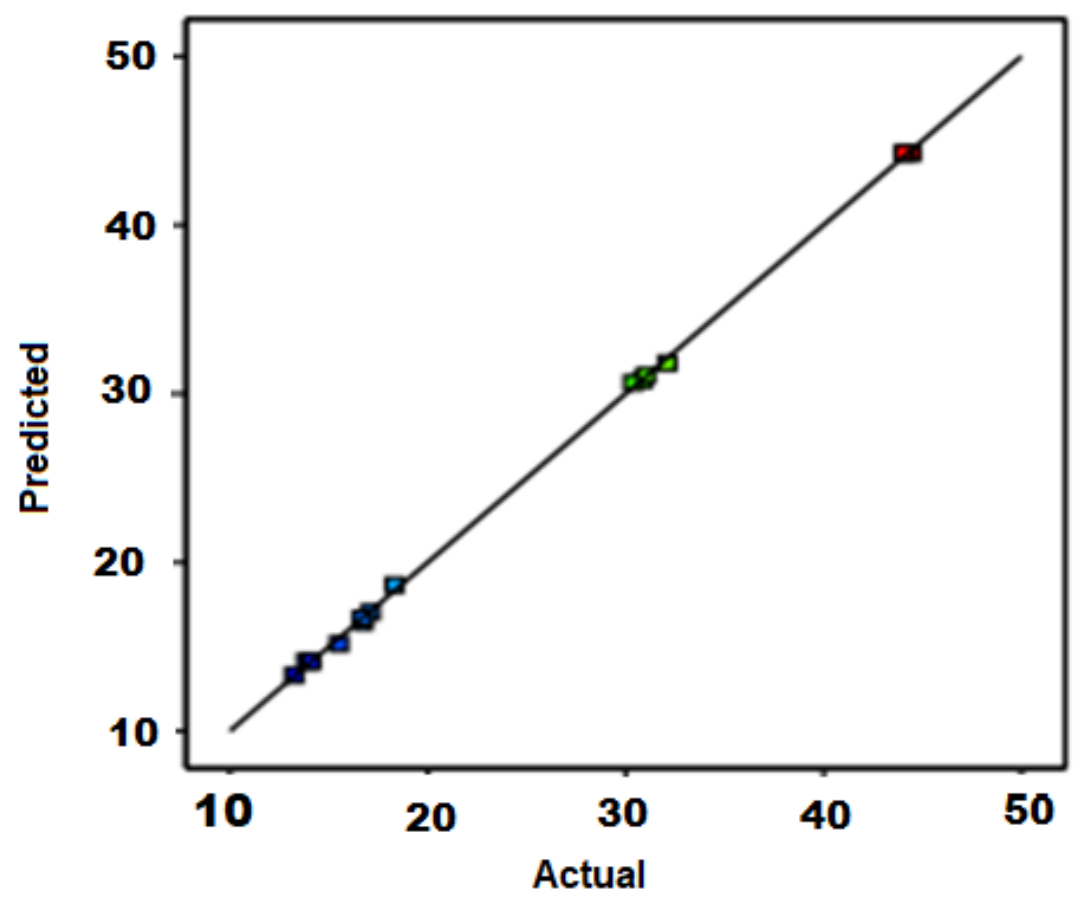

Figure 4. Actual and predicted carbon yield derived from the RSM Model.

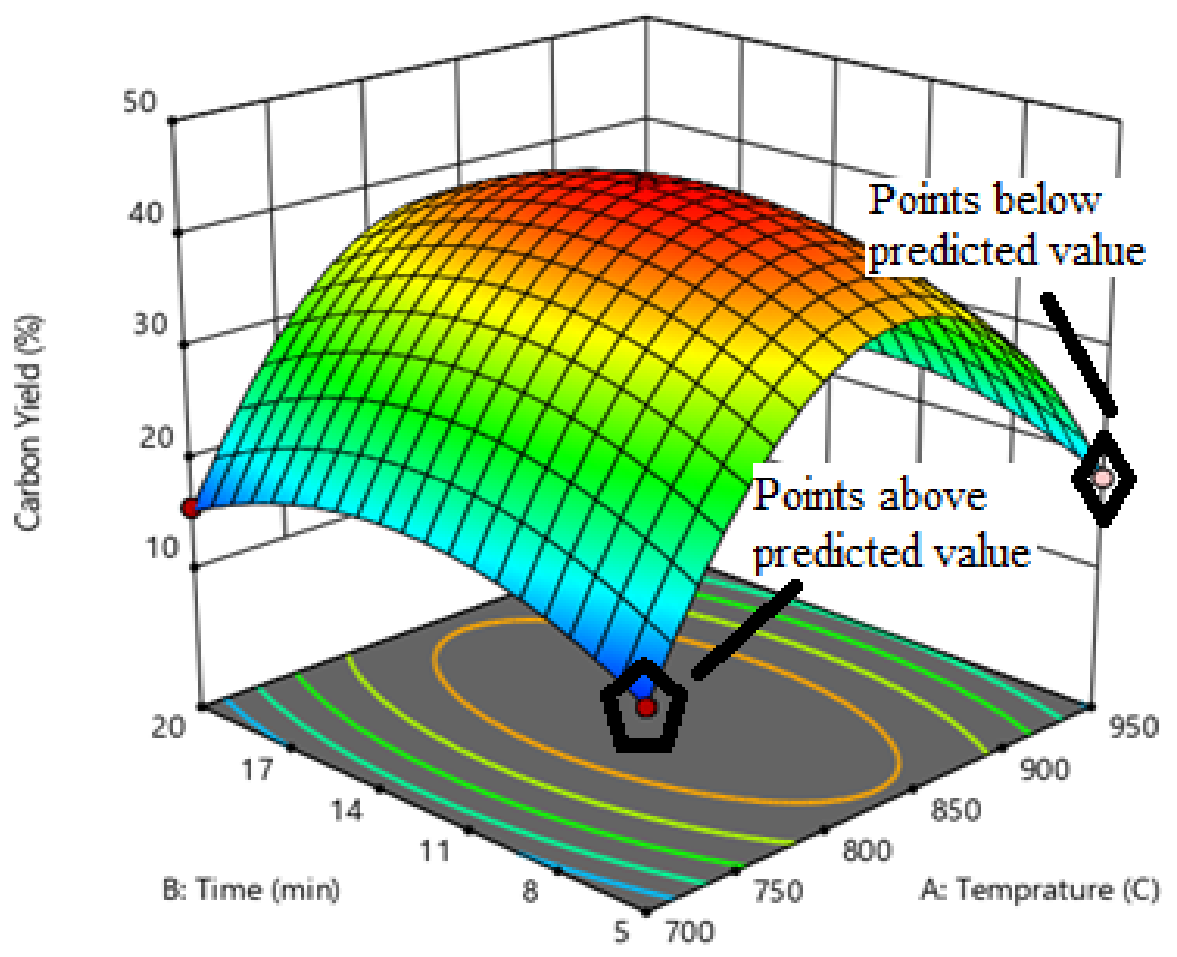

Figure 5. Effects of variables on carbon yield. 
Table 6. ANOVA of Box-Behnken design for the dependent variable (carbon yield) in terms of independent variables (different process parameters).

\begin{tabular}{|c|c|c|c|c|c|c|}
\hline Scheme & Sum of Squares & Df & Mean Square & F-Value & $p$-Value & Significance \\
\hline Model & 1975.25 & 9 & 219.47 & 1722.93 & $<0.0001$ & significant \\
\hline A-Temperature & 18.42 & 1 & 18.42 & 144.62 & $<0.0001$ & - \\
\hline B-Time & 0.4050 & 1 & 0.4050 & 3.18 & 0.1347 & - \\
\hline $\begin{array}{c}\text { C-Catalyst } \\
\text { Weight }\end{array}$ & 1.05 & 1 & 1.05 & 8.25 & 0.0349 & - \\
\hline $\mathrm{AB}$ & 2.27 & 1 & 2.27 & 17.78 & 0.0084 & - \\
\hline $\mathrm{AC}$ & 0.0110 & 1 & 0.0110 & 0.0865 & 0.7804 & - \\
\hline $\mathrm{BC}$ & 0.0870 & 1 & 0.0870 & 0.6832 & 0.4461 & - \\
\hline$A^{2}$ & 1784.57 & 1 & 1784.57 & $14,009.47$ & $<0.0001$ & - \\
\hline $\mathrm{B}^{2}$ & 138.73 & 1 & 138.73 & 1089.05 & $<0.0001$ & - \\
\hline$C^{2}$ & 184.02 & 1 & 184.02 & 1444.59 & $<0.0001$ & - \\
\hline Residual & 0.6369 & 5 & 0.1274 & - & - & - \\
\hline Lack of Fit & 0.5524 & 3 & 0.1841 & 4.36 & 0.1922 & not significant \\
\hline Pure Error & 0.0845 & 2 & 0.0422 & - & - & - \\
\hline Cor Total & 1975.89 & 14 & - & - & - & - \\
\hline
\end{tabular}

Equation (4), with regard to actual factors, can be utilized to predict the response of dependent variable for several given levels of each factor. Developed on model fitting and multiple linear regression, the appropriate model was selected to resolve the interactions of the response function with the selected factors.

$$
\mathrm{Y}=\mathrm{ao} \sum_{\mathrm{i}=1}^{4} \mathrm{aixi}+\sum_{\mathrm{i}=1}^{4} \operatorname{aiix} 2 \mathrm{i}+\sum_{\mathrm{i}=1}^{4} \text { aijxixj }
$$

where $\mathrm{Y}=$ Response, $\mathrm{a}_{0}=$ Constant coefficient, $\mathrm{a}_{\mathrm{i}}, \mathrm{a}_{\mathrm{ii}}$, and $\mathrm{a}_{\mathrm{ij}}=$ are the coefficients predicted by regression for linear, quadratic, and crossproduct effects of $\mathrm{X}_{1}, \mathrm{X}_{2}$, and $\mathrm{X}_{3}$, respectively.

In this study, the variables $\mathrm{X}_{1}, \mathrm{X}_{2}$ and $\mathrm{X}_{3}$ were allocated for reaction temperature [A], reaction time [B], weight of catalyst $[\mathrm{C}]$, and time of reaction [35].

\subsection{Temperature Effects on Growth of CNTs}

To analyze the effects of temperature on carbon yield a three-dimensional response surface curve was used as illustrated in Figure 6. To analyze the potential effects of the independent variables on the dependent variable (carbon yield), curves were obtained. The carbon yield was maximized with the catalyst load of $100 \mathrm{mg}$ at around $800-850{ }^{\circ} \mathrm{C}$. However, at higher temperatures $\left(850-900{ }^{\circ} \mathrm{C}\right)$, vapors of hydrocarbon passed out of the crucible quickly, which caused a reduction in the hydrocarbon source for CNT growth.

\subsection{Reaction Time and CNTs Growth}

Figure 7 illustrates how the reaction time affects CNT growth. In all the experiments, the poultry waste weight $(4 \mathrm{~g})$ was kept constant. It was observed that CNT yield continuously decreased as the reaction time within the tube furnace increased. For 10-12 min, the contact of hydrocarbon vapors with catalysts particles was observed after which the carbon-rich vapors started leaving the porcelain boat. Twelve minutes of contact time was optimal. The exposure of samples to a higher temperature for a longer time resulted in the oxidation of hydrocarbons, which was the major cause of the reduction in CNT yield [36]. 


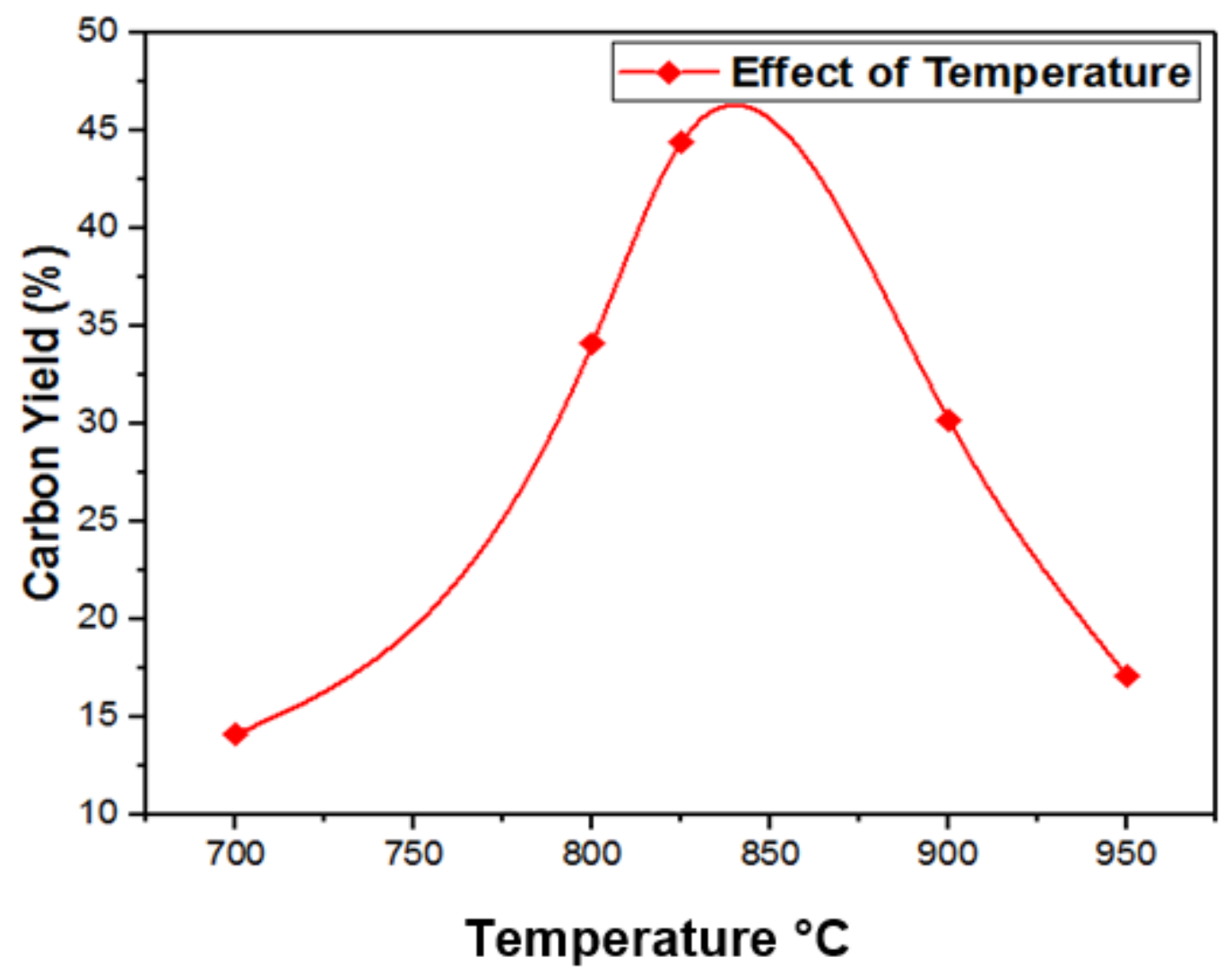

Figure 6. Changes in percent carbon yield with change in temperature.

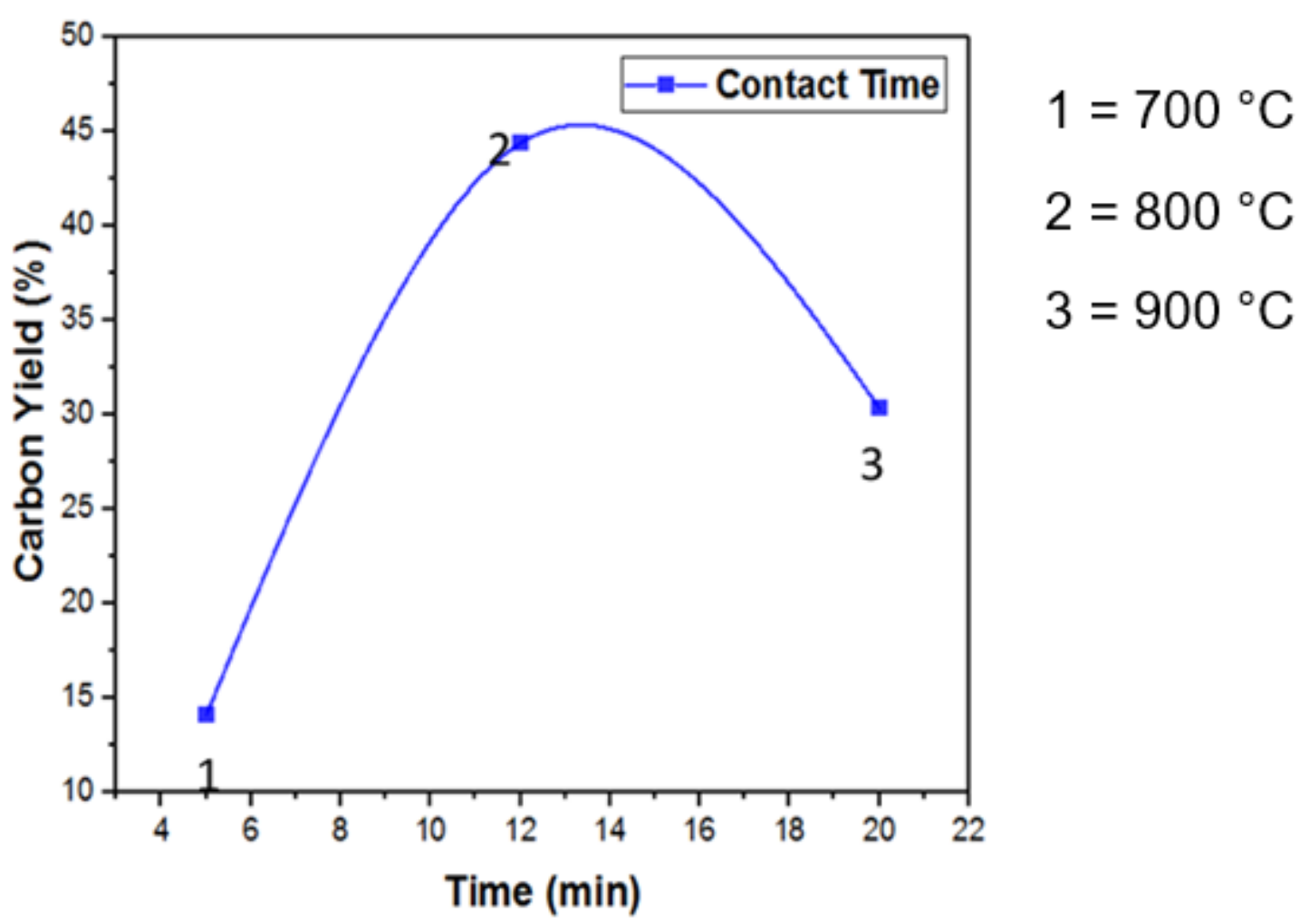

Figure 7. Effect of optimized contact time on carbon yield. 


\subsection{Catalyst Characterization}

3.6.1. X-ray Diffraction (XRD)

Figure 8 illustrates the $\mathrm{Ni} / \mathrm{Mo} / \mathrm{MgO}$ (4:0.2:1) catalyst diffraction. In these patterns, the intense peaks at $37.30^{\circ}$ and $43.28^{\circ}$ corresponded to $\mathrm{Mg}$ and $\mathrm{MoNi}$ respectively. It was confirmed that $\mathrm{Ni}$ and $\mathrm{Mo}$ particles were well supported over the $\mathrm{MgO}$ matrix and sintering was not observed due to the presence of sharp peaks [37].

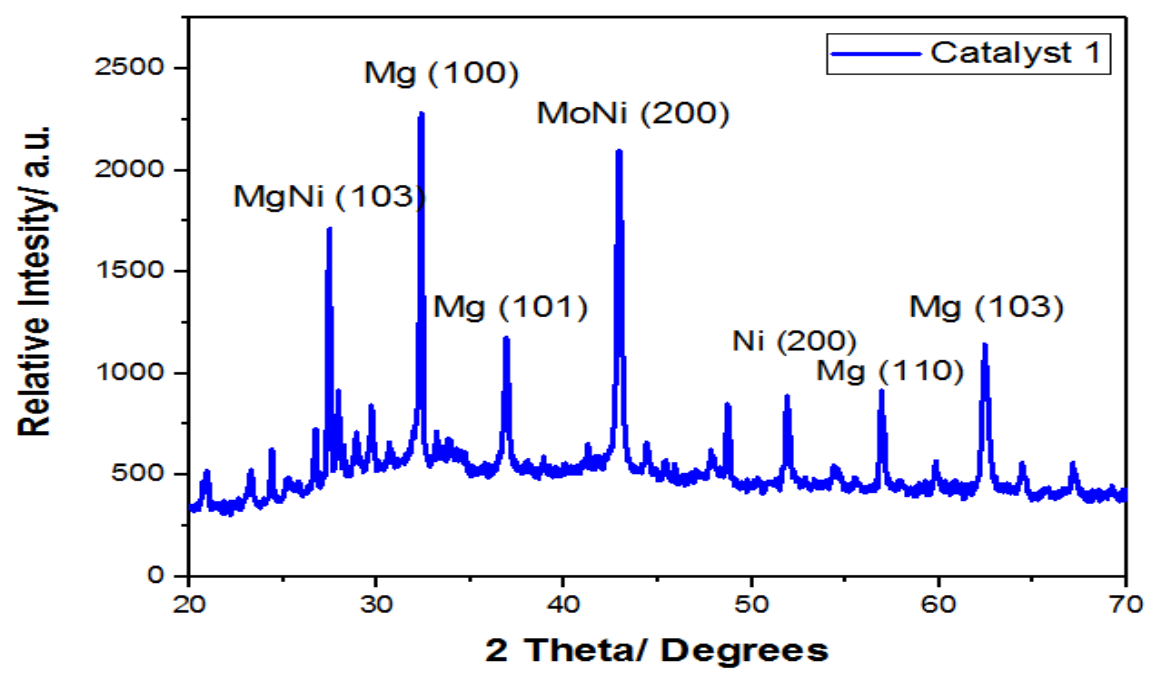

Figure 8. XRD of the optimized molar ratio of $\mathrm{Ni} / \mathrm{Mo} / \mathrm{Mg}(4: 0.2: 1)$ catalyst.

\subsubsection{Morphological Analysis of the Catalyst}

Scanning Electron Microscopy (SEM) procured from Jeol, Tokyo, Japan was utilized in this study to examine the surface morphologies of various samples. The morphology of the $\mathrm{Ni} / \mathrm{Mo} / \mathrm{MgO}$ catalyst particle with an average size of $18 \mathrm{~nm}$ at $\times 100,000 /$ - magnification is depicted in Figure 9b. The size of the nanoparticles did not depend on the specific magnification. A uniform catalyst layer with a good distribution of $\mathrm{Ni}, \mathrm{Mo}$, and $\mathrm{MgO}$ (4:0.2:1) particles was observed from the catalyst morphology. The metal particles appeared as individual crystals as well as in segregated form. Due to the dark and spherical shape of both $\mathrm{Ni}$ and Mo, it was challenging to discern the Ni and Mo particles as shown in Figure 9a. The Mg matrix well incorporated the $\mathrm{Ni}$ and Mo particles as shown from the microstructure of $\mathrm{Ni} / \mathrm{Mo} / \mathrm{MgO}$. Several $\mathrm{Mg}-\mathrm{Mo}$ and $\mathrm{Ni}-\mathrm{Mo}$ phases for the $\mathrm{Ni} / \mathrm{Mo} / \mathrm{MgO}$ catalyst were shown by the XRD report; therefore, these results agreed with XRD result.
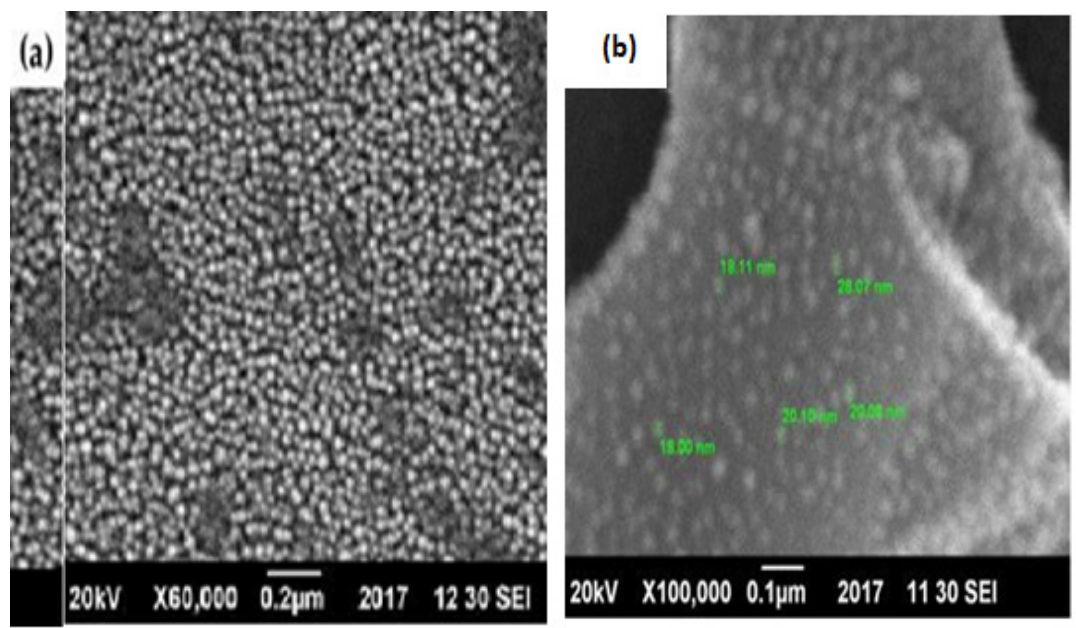

Figure 9. SEM of the catalyst with the ratio of $\mathrm{Ni}_{4} \mathrm{Mo}_{0.2} \mathrm{MgO}_{1}$. (a) $\mathrm{Ni}$ and Mo particles (b) Morphology of $\mathrm{Ni} / \mathrm{Mo} / \mathrm{MgO}$ catalyst particles with average size of $18 \mathrm{~nm}$. 


\subsection{Characterization of CNTs}

XRD, SEM, and HRTEM techniques were used to study the effects of the various mole ratios of $\mathrm{Ni} / \mathrm{Mo} / \mathrm{Mg}$ on $\mathrm{CNT}$ yield.

\subsubsection{X-ray Diffraction (XRD)}

The XRD patterns of purified CNTs after synthesis over $0.1 \mathrm{~g}$ of $\mathrm{Ni} / \mathrm{Mo} / \mathrm{MgO}$ catalyst at $825^{\circ} \mathrm{C}$, time of combustion $=12 \mathrm{~min}$, and $4 \mathrm{~g}$ of poultry litter are shown in Figure 10 . The well-resolved graphite $\left(\begin{array}{ll}0 & 0\end{array}\right)$ peak at $2 \theta=26.62^{\circ}$ was observed, which indicates the growing of CNTs. During the synthesis of CNTs, carbon was diffused into Mo and No nanoparticles, and Mo was converted to a Mo carbide phase ( $\mathrm{MoC}$ and $\mathrm{Mo}_{2} \mathrm{C}$ ) [34]. Carbon nanotube bundles were formed due to the carbon atoms' precipitation that occurred on the Ni-Mo crystal plane. Carbon atom precipitation on the surface of catalyst occurred when more carbon atoms diffused on Ni and Mo nanoparticles. For purified CNT, the XRD pattern as depicted in Figure 10 showed a sharp peak $\left(\begin{array}{ll}0 & 0\end{array}\right)$ with high intensity, which indicated the absence of amorphous carbon [38]. The peak at $2 \theta=44.60^{\circ}$ was caused by the presence of Ni particles in the CNT product. When the CNTs were purified, a decrease in peak intensity was observed. In the purification step, the partial removal of the catalyst particles through acid treatment were confirmed. However, it was challenging to ascertain the \% removal of impurities from the characterization of purified CNT as it appeared similar to the CNTs, which were not purified [39].

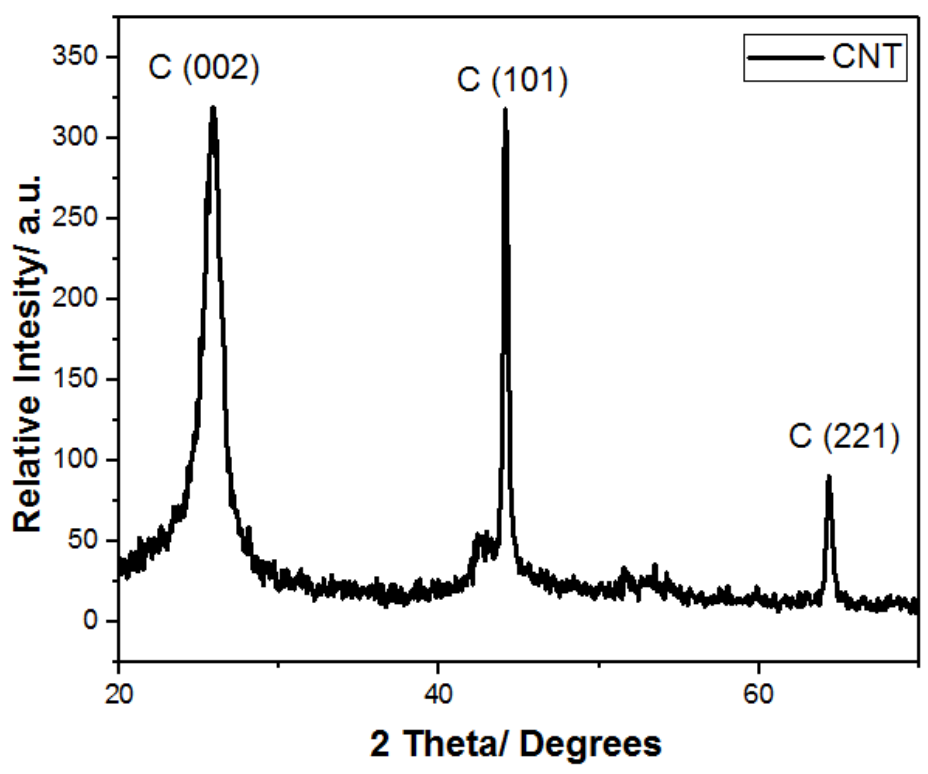

Figure 10. XRD of purified CNTs.

\subsubsection{Raman Spectroscopy}

Raman spectra results showed two characteristic bands at $1340 \pm 5 \mathrm{~cm}^{-1}$ and $1580 \pm 5 \mathrm{~cm}^{-1}$ as shown in Figure 11. The band at $1340 \mathrm{~cm}^{-1}$ was denoted as D (disorder) mode, which corresponded to the local structural impurities, defects, and disorder. The band at $1580 \mathrm{~cm}^{-1}$ was attributed to the $\mathrm{G}$ (graphite) mode, which corresponded to the degree of graphitization of the MWCNTs [40]. A minor displacement of D and G mode for the samples was observed and the peak intensity ratio was found to be 0.85 . For purified CNTs, the lower peak intensity ratio was caused by graphene layer distortion. This occurred during treatment with concentrated $\mathrm{HCl}$. 


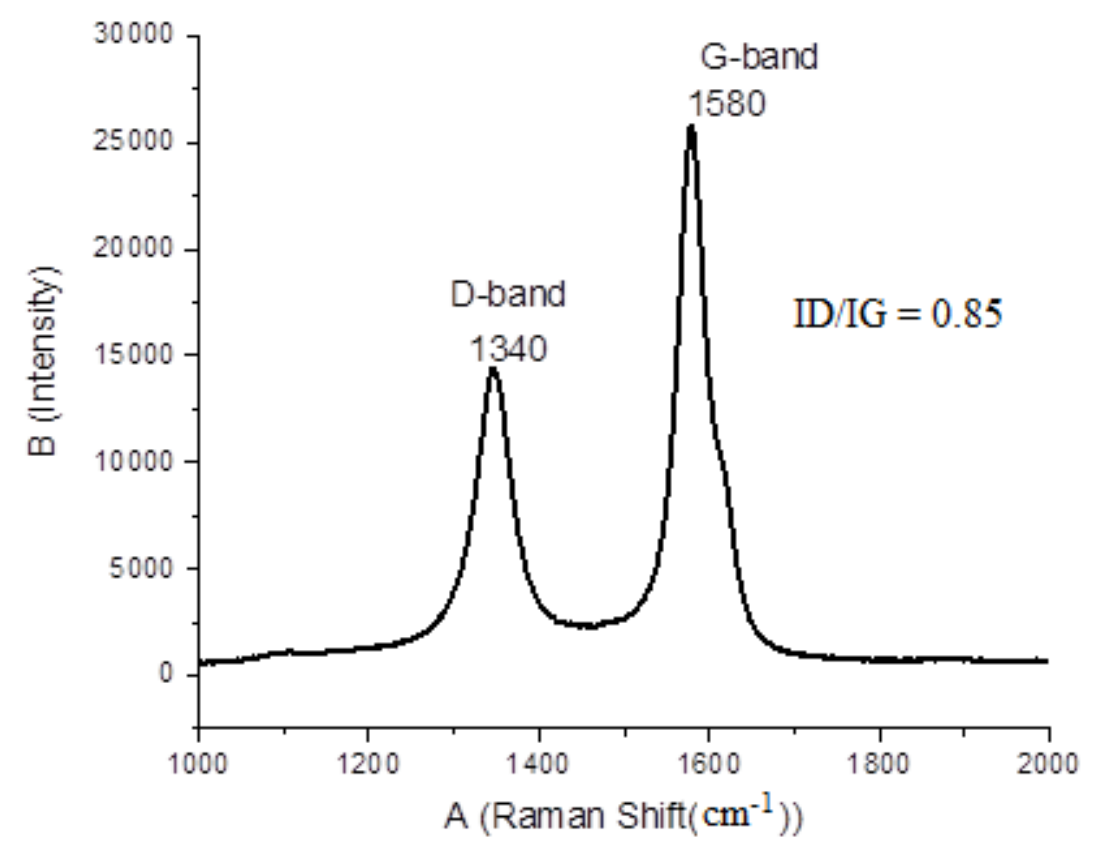

Figure 11. Raman spectra of CNTs synthesized at $825{ }^{\circ} \mathrm{C}$ with $12 \mathrm{~min}$ combustion time over a Ni4Mo0.2MgO1 catalyst.

\subsubsection{Morphological Analysis of CNTs}

Scanning electron microscopy (SEM) and transmission electron microscopy (TEM) micrographs of synthesized CNTs over the $\mathrm{Ni} / \mathrm{Mo} / \mathrm{Mg}$ (4:0.2:1) catalyst are shown in Figure 12. It was very challenging to ascertain the percent of impurity removed from the SEM image of the CNT, which was purified, as it looks similar to the one of unpurified CNTs. Longer CNTs were produced when the exposure for hydrocarbon was maximized, which was provided by the catalysts at the tip of the CNTs [41]. The size of the synthesized CNTs at $\times 75,000$ magnifications was $26 \mathrm{~nm}$.

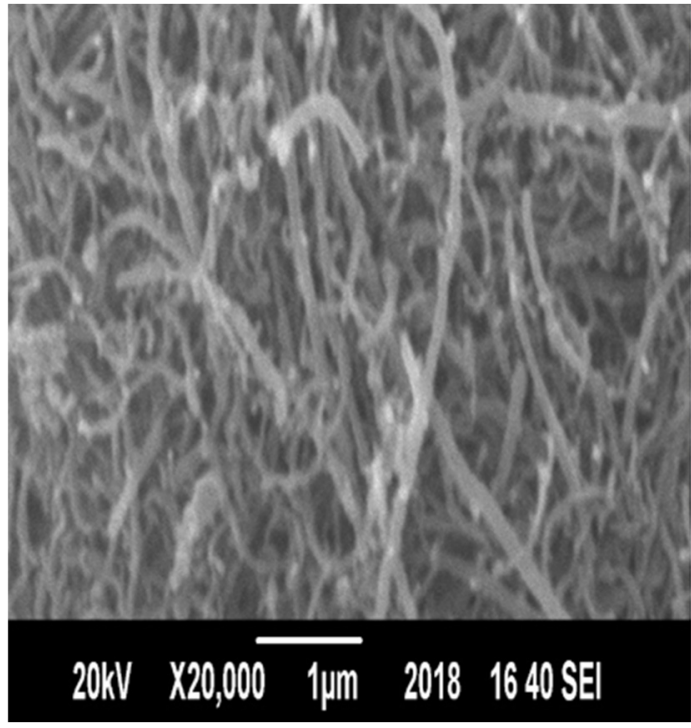

(a)

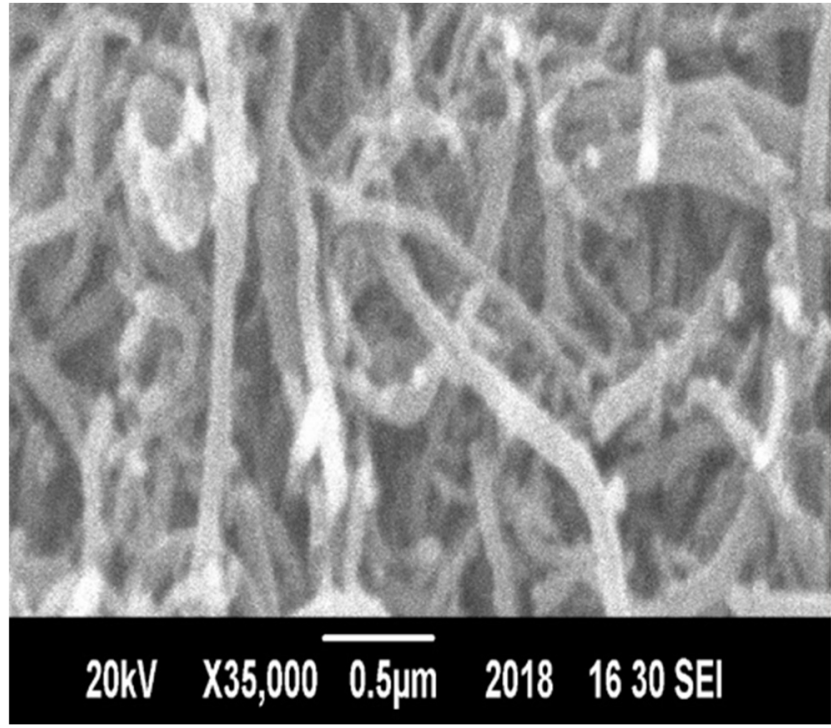

(b)

Figure 12. Cont. 


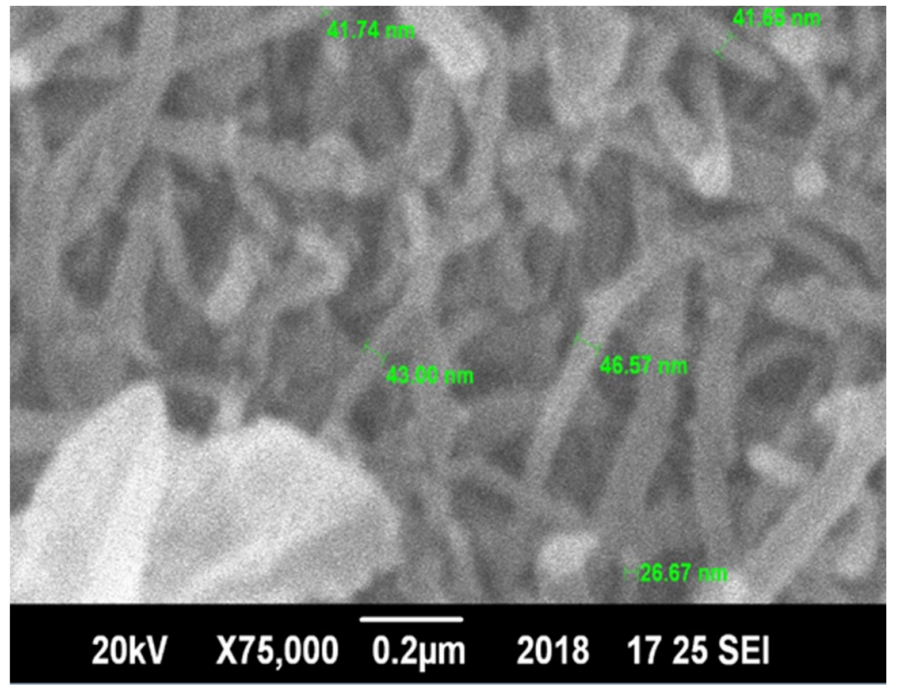

(c)

Figure 12. Scanning electron micrographs of synthesized CNTs at different magnifications mentioned on each subfigure (a-c).

A high-resolution transmission electron microscope (HRTEM) was used to characterize the size and structure of nanomaterials. Figure 13 shows the CNTs obtained at the growth time of $12 \mathrm{~min}$, using the catalyst Ni4Mo0.2MgO1 which was covered by many graphitized layers. These were (a) $200 \mathrm{~nm}$ MWCNTs with well-aligned graphene walls (b) $100 \mathrm{~nm}$ with distorted graphene walls and (c) $50 \mathrm{~nm}$ MWCNTs. Thus, the purity and graphitization of CNTs were enhanced with growth time. The TEM images showed the purified MWCNTs in which the long intertwined CNTs were not entirely clean but most impurities had been removed. Despite purification with acid treatment, the produced CNTs contained a minute amount of impurities such as amorphous carbon, fullerenes, and catalyst particles which could be observed as a black spot in the TEM image as shown in Figure 13. Thus, the purification for MWCNTs was not very effective in this study, which is a serious issue if CNTs need to be used directly as a functional filler in composite materials. TEM observations show that the most probable diameters of nanotubes are around about $50 \mathrm{~nm}$.
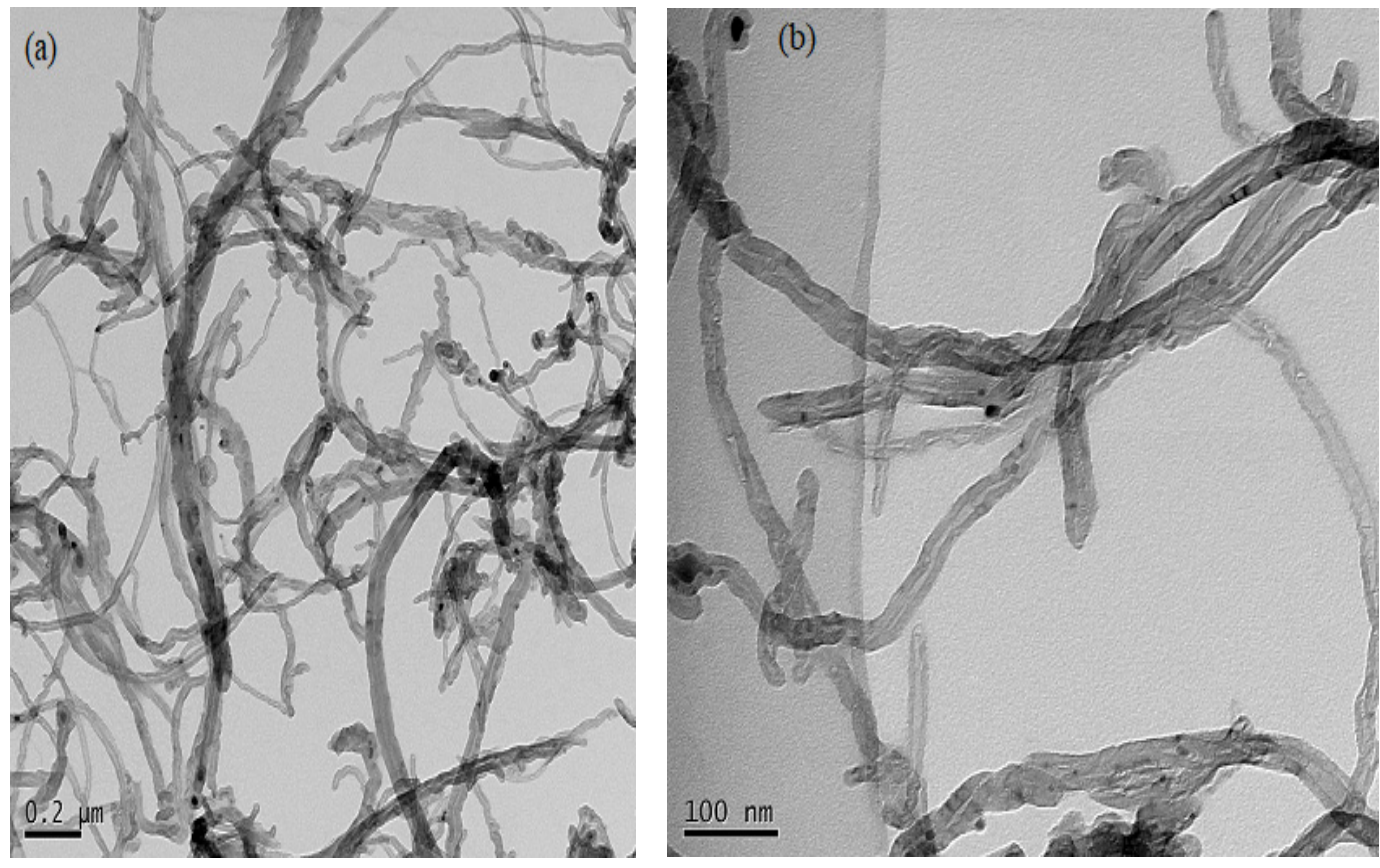

Figure 13. Cont. 


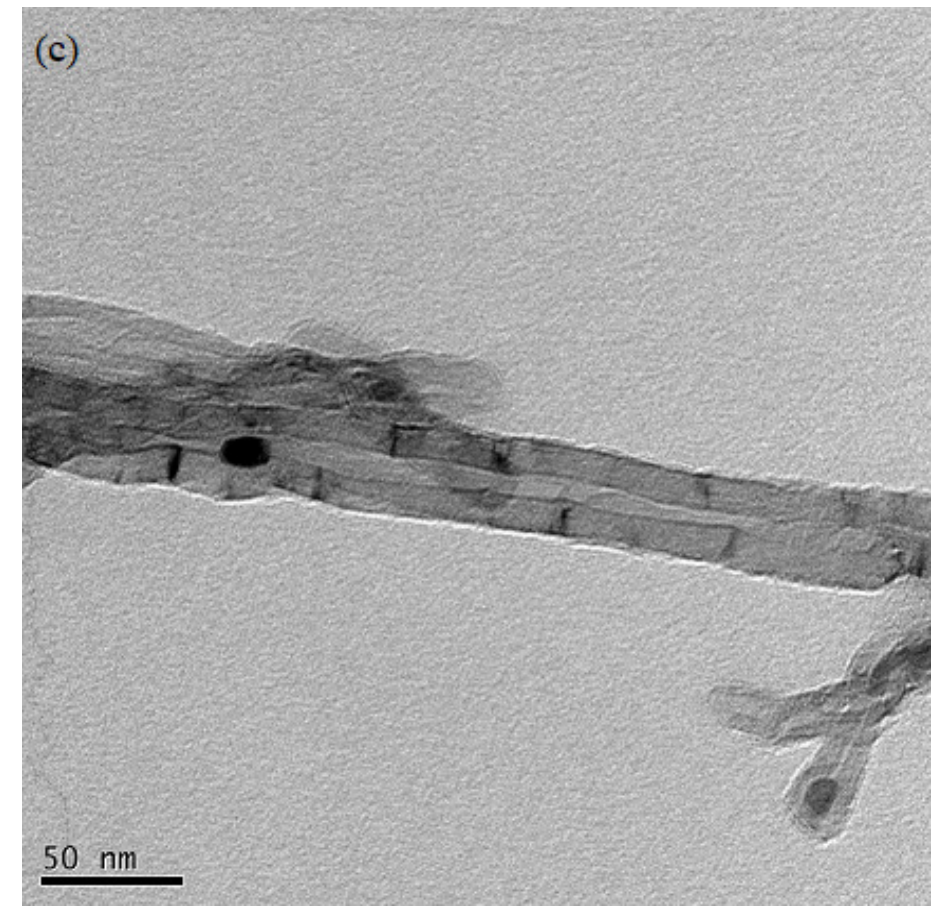

Figure 13. HRTEM images of purified MWCNTs (a) $0.2 \mu \mathrm{m}$, (b) $100 \mathrm{~nm}$, and (c) $50 \mathrm{~nm}$.

\subsection{Adsorption of $\mathrm{Cr}(\mathrm{VI})$}

Synthesized MWCNTs were used to remove chromium from synthetic wastewater. Using MWCNTs in $2.8 \mathrm{~h}, \mathrm{pH}=3$, and $\mathrm{rpm}=400$, approximately $81.83 \%$ of $\mathrm{Cr}(\mathrm{VI})$ was removed for a quantity of 2-8 $\mathrm{mg}$ of CNTs. Using MWCNTs, the amount of $\mathrm{Cr}(\mathrm{VI})$ removed from wastewater was approximately $78.8 \%$ [42]. To remove heavy metals from aqueous solution, as per these studies, the CNTs are excellent adsorbents.

\subsubsection{Effect of $\mathrm{pH}$}

For controlling the $\mathrm{Cr}(\mathrm{VI})$ adsorption process, the system $\mathrm{pH}$ was observed as one of the key parameters in this study. The maximum removal efficiency of $\mathrm{Cr}(\mathrm{VI})$ was higher at a low $\mathrm{pH}$ as shown in Figure 14. The optimum $\mathrm{pH}$ was observed at $\mathrm{pH} 3.0$ and the remaining trials were performed at this $\mathrm{pH}$. With an increase in $\mathrm{pH}$, the negative charge on the CNTs' surface increased. Due to this, repulsion was observed between the CNTs and Cr (VI). Therefore, with an increase in $\mathrm{pH}$ a decrease in removal efficiency was observed. [43]. Different results were obtained with varying $\mathrm{pH}$ values. This means the removal process was highly related to the variations in $\mathrm{pH}$ of the solution. It was observed that as the $\mathrm{pH}$ values increased from 2.0 to 7.0 the adsorption capacity decreased. This observable fact is explained due to the presence of different forms of $\mathrm{Cr}(\mathrm{VI})$ in the aqueous phase. The dominant forms of $\mathrm{Cr}(\mathrm{VI})$ were $\mathrm{Cr}_{2} \mathrm{O}_{7}{ }^{-2}$ and $\mathrm{HCrO}_{4}{ }^{-2}$ ions in the $\mathrm{pH}$ range of 2-7. MWCNTs' surfaces, at low $\mathrm{pH}$, became positively charged due to the protonation effect and thus $\mathrm{Cr}$ (VI) adsorption was enhanced due to the electrostatic forces between the MWCNTs and the negatively charged $\mathrm{Cr}_{2} \mathrm{O}_{7}{ }^{-2}$ and $\mathrm{HCrO}_{4}{ }^{-2}$ ions [44]. While $\mathrm{CrO}_{4}{ }^{-2}$ ions prevailed in the solution at higher $\mathrm{pH}$ values, the MWCNTs surface protonation decreased, and the adsorption efficiency was thus decreased [45]. 


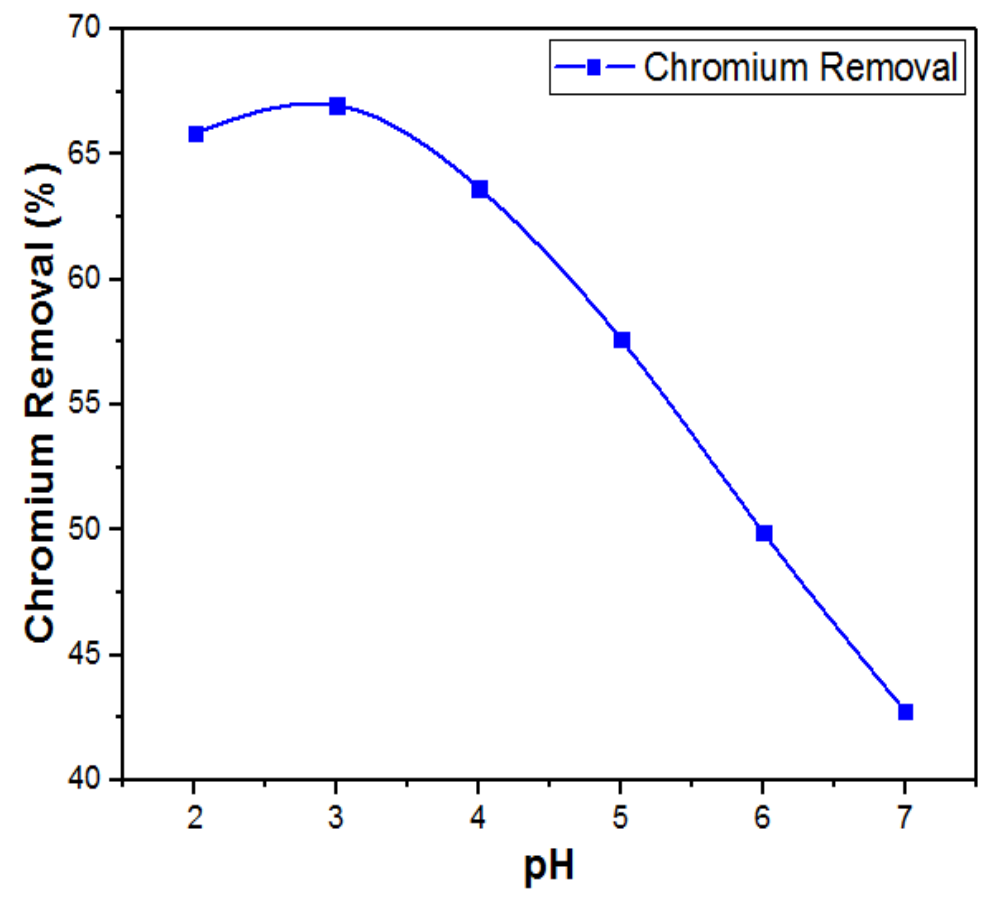

Figure 14. Effects of $\mathrm{pH}$ on removal of $\mathrm{Cr}(\mathrm{VI})$.

\subsubsection{Effect of Adsorbent Dosage on Chromium Removal}

With an increase in the adsorbent dosage from 2 to $8 \mathrm{mg}$, keeping all the other parameters constant, the removal of Cr (VI) increased. This is illustrated in Figure 15. The highest removal rate was observed at low concentrations of the adsorbent. This is because the number of active sites is higher at lower adsorbent concentrations. However, it decreased as the aggregation of particles occurred at a higher concentration of the adsorbent dosage.

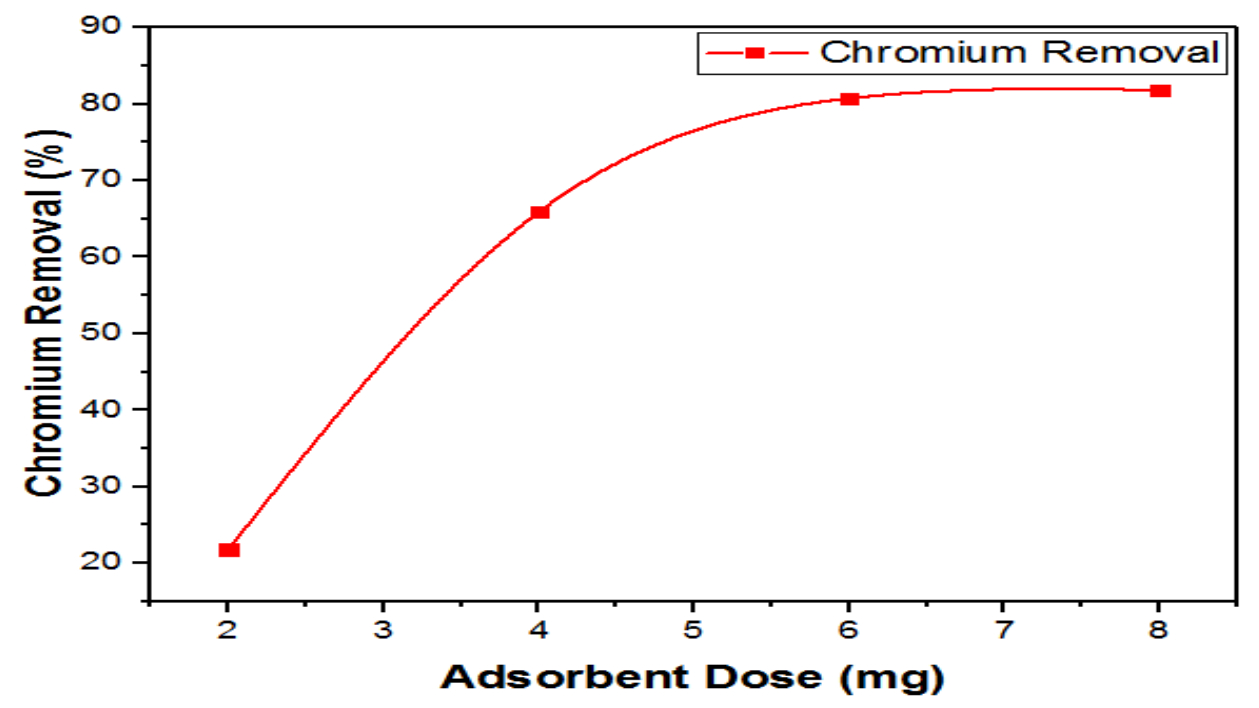

Figure 15. Effects of adsorbent dosage on removal of $\mathrm{Cr}(\mathrm{VI})$.

In the higher adsorbent dosage, in contrast to the lower dosage, the capacity of adsorption was not fully utilized. Consequently, it is possible that with an increase in adsorbent dosage the capacity of adsorption may decrease [46]. 


\subsubsection{Effect of Adsorption Contact Time}

The removal efficiency of $\mathrm{Cr}(\mathrm{VI})$ was increased to $81 \%$ as the time of adsorption increased from 30 to $200 \mathrm{~min}$ at $\mathrm{pH} 3$ and an adsorbent (MWCNTs) dose of $8 \mathrm{mg}$. The maximum removal was noted at $180 \mathrm{~min}$ of adsorption time as shown in Figure 16. The surface coverage of the adsorbent was higher as time progressed, and no further adsorption occurred [30].

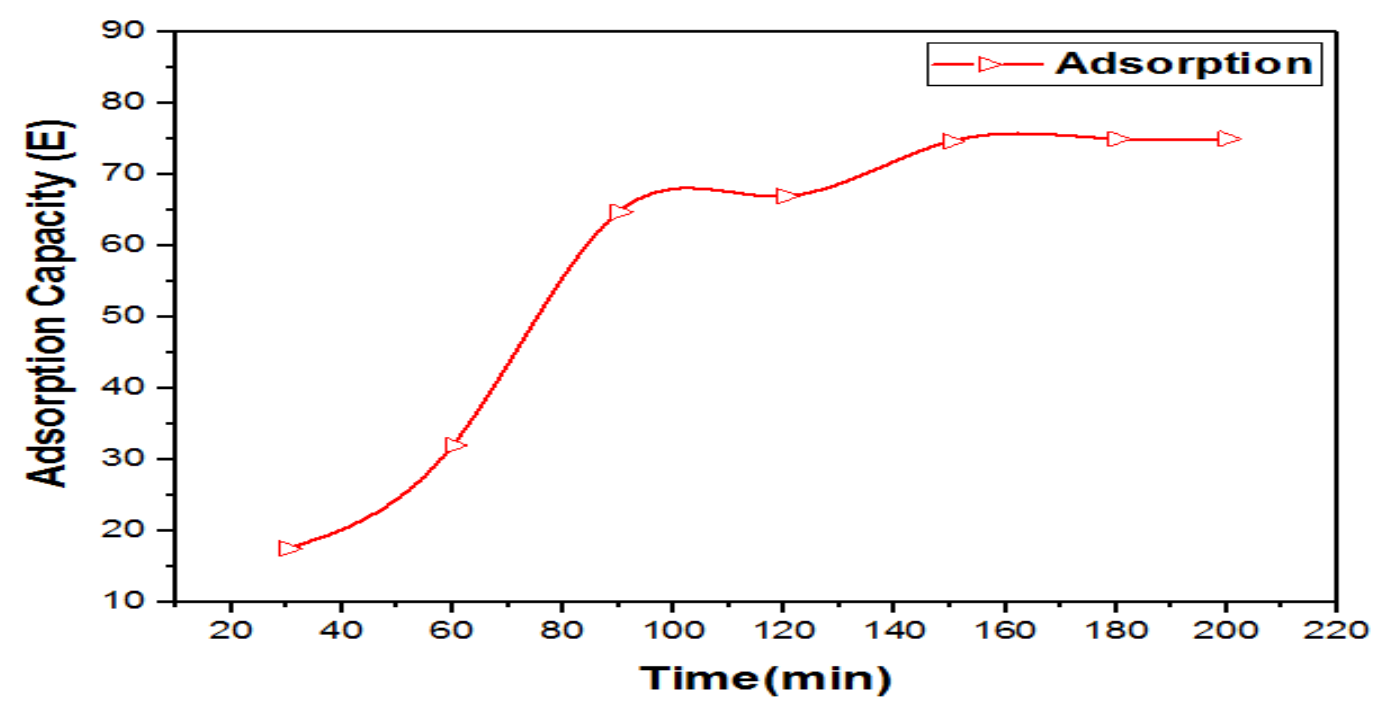

Figure 16. Effect of contact time on the adsorption process.

\section{Conclusions}

Poultry litter was used as a hydrocarbon source for CNT production. The Response Surface Methodology (RSM) was adopted to optimize the Ni/Mo/MgO mole ratio. Among them, $\mathrm{Ni}$ metal was found to have the highest proportion as compared to $\mathrm{Mo}$ and $\mathrm{MgO}$. Poultry waste as a hydrocarbon source was combusted in the presence of a $\mathrm{Ni} / \mathrm{Mo} / \mathrm{MgO}$ catalyst in an electrically heated tube furnace for the growth of CNTs. A high yield of CNTs was obtained using an optimized molar ratio $(\mathrm{Ni} / \mathrm{Mo} / \mathrm{MgO}$ (4:0.2:1) of catalytic precursors at $825^{\circ} \mathrm{C}, 4 \mathrm{~g}$ poultry litter weight, $100 \mathrm{mg}$ catalyst weight, with $12 \mathrm{~min}$ of combustion time.

The synthesized CNTs were used in wastewater treatment for the removal of $\mathrm{Cr}$ (VI) because MWCNTs exhibited excellent adsorption properties. The adsorption efficiency by MWCNTs was increased with a high adsorbent dosage, but the equilibrium adsorption capacity decreased considerably. As the $\mathrm{pH}$ value was increased the adsorption capacity was found to decrease. A maximum adsorption of $\mathrm{Cr}$ (VI) from synthetic wastewater by synthesized MWCNTs was noted at $82.0 \%$. Adsorbed chromium can be used as a catalyst. Chromium-based catalysts are highly valuable for ethylene polymerization, and oligomerization catalysts are broadly applied for the industrial production of polyethylene and 1-hexene.

Author Contributions: Conceptualization, N.H. and Y.J.; Methodology, N.H. and M.A.B.; Software, X.Y., and S.N.K.; Validation, N.H., M.A.B., Y.J. and S.N.K.; Resources, IESE and NUST.; Data curation, N.H.; Writing, N.H., M.A.B. and Y.J.; Review and editing, N.H., S.N.K. and M.W.; Visualization, X.Y. and M.W.; Supervision, M.A.B. and Y.J.; Project administration, IESE and NUST. All authors have read and agreed to the published version of the manuscript.

Funding: This research received no external funding. Financial support for carrying out this study was provided by the Institute of Environmental Sciences and Engineering (IESE), NUST.

Institutional Review Board Statement: Not applicable.

Informed Consent Statement: Not applicable. 
Data Availability Statement: The data presented in this study are available on request from the corresponding author.

Acknowledgments: We, all the authors, very gratefully acknowledge the support of National University of Sciences and Technology (NUST) for extending every possible support such as financial support, lab facilities, and so forth to complete this research. This work would not be possible without the support of the university.

Conflicts of Interest: All authors declare no conflicts of interest.

\section{References}

1. Liaqat, I. Pakistan poultry industry growth and challenges. Approach Poult Dairy Veterin Sci. 2018, 2, 174-175. [CrossRef]

2. Hussain, J.; Rabbani, I.; Aslam, S.; Ahmad, H.A. An overview of poultry industry in Pakistan. World's Poult. Sci. J. 2015, 71, 689-700. [CrossRef] [PubMed]

3. Santos Dalólio, F.; da Silva, J.N.; Carneiro de Oliveira, A.C.; Ferreira Tinôco, I.d.F.; Christiam Barbosa, R.; Resende, M.D.O.; Teixeira Albino, L.F.; Teixeira Coelho, S. Poultry litter as biomass energy: A review and future perspectives. Renew. Sustain. Energy Rev. 2017, 76, 941-949. [CrossRef]

4. Ali, S.; Ali, S.; Riaz, B. Estimation of Technical Efficiency of Open Shed Broiler Farmers in Punjab, Pakistan: A Stochastic Frontier Analysis. J. Econ. Sustain. Dev. 2014, 5, 79-88.

5. Leytem, A.B.; Plumstead, P.W.; Maguire, R.O.; Kwanyuen, P.; Burton, J.W.; Brake, J. Interaction of Calcium and Phytate in Broiler Diets. 2. Effects on Total and Soluble Phosphorus Excretion. Poult. Sci. 2008, 87, 459-467. [CrossRef] [PubMed]

6. Ullah, I.; Ali, S.; Ullah Khan, S.; Sajjad, M. Assessment of technical efficiency of open shed broiler farms: The case study of Khyber Pakhtunkhwa province Pakistan. J. Saudi Soc. Agric. Sci. 2019, 18, 361-366. [CrossRef]

7. Singh, A.A.; Alhattab, M.K. Drying poultry manure for pollution potential reduction and production of organic fertilizer. Am. J. Environ. Sci. 2013, 9, 88-102. [CrossRef]

8. Jiang, Z.C.A.X. Microbiological Safety of Chicken Litter or Chicken Litter-Based Organic Fertilizers: A Review. Agriculture 2014, 4, 1. [CrossRef]

9. Chan, K.Y.; Van Zwieten, L.; Meszaros, I.; Downie, A.; Joseph, S. Using poultry litter biochars as soil amendments. Soil Res. 2008, 46, 437-444. [CrossRef]

10. Lima, I.; Marshall, W.E. Utilization of turkey manure as granular activated carbon: Physical, chemical and adsorptive properties. Waste Manag. 2005, 25, 726-732. [CrossRef]

11. Ng, S.W.L.; Yilmaz, G.; Ong, W.L.; Ho, G.W. One-step activation towards spontaneous etching of hollow and hierarchical porous carbon nanospheres for enhanced pollutant adsorption and energy storage. Appl. Catal. B 2018, 220, 533-541. [CrossRef]

12. Kim, S.-W.; Behera, S.K.; Jamal, Y.; Park, H.-S. Optimization of Sodium Hydrosulfide Synthesis for Metal Recovery from Wastewater Using Flue Gas Containing H2S. J. Environ. Eng. 2016, 142, C40150091-C40150097. [CrossRef]

13. Khoso, W.A.; Haleem, N.; Baig, M.A.; Jamal, Y. Synthesis, characterization and heavy metal removal efficiency of nickel ferrite nanoparticles (NFN's). Sci. Rep. 2021, 11, 3790. [CrossRef] [PubMed]

14. Hassan, M.M.; Haleem, N.; Baig, M.A.; Jamal, Y. Phytoaccumulation of heavy metals from municipal solid waste leachate using different grasses under hydroponic condition. Sci. Rep. 2020, 10, 15802. [CrossRef] [PubMed]

15. Zhong, R.; Sels, B.F. Sulfonated mesoporous carbon and silica-carbon nanocomposites for biomass conversion. Appl. Catal. $B$ 2018, 236, 518-545. [CrossRef]

16. Hoyos-Palacio, L.M.; García, A.G.; Pérez-Robles, J.F.; González, J.; Martínez-Tejada, H.V. Catalytic effect of Fe, Ni, Co and Mo on the CNTs production. IOP Conf. Ser. Mater. Sci. Eng. 2014, 59, 012005. [CrossRef]

17. Mamalis, A.G.; Vogtländer, L.O.G.; Markopoulos, A. Nanotechnology and nanostructured materials: Trends in carbon nanotubes. Precis. Eng. 2004, 28, 16-30. [CrossRef]

18. Zhu, Z.; Chan, Y.-C.; Chen, Z.; Gan, C.-L.; Wu, F. Effect of the size of carbon nanotubes (CNTs) on the microstructure and mechanical strength of CNTs-doped composite Sn0.3Ag0.7Cu-CNTs solder. Mater. Sci. Eng. A 2018, 727, 160-169. [CrossRef]

19. Yao, Y.; Lian, C.; Wu, G.; Hu, Y.; Wei, F.; Yu, M.; Wang, S. Synthesis of "sea urchin"-like carbon nanotubes/porous carbon superstructures derived from waste biomass for treatment of various contaminants. Appl. Catal. B 2017, 219, 563-571. [CrossRef]

20. Tripathi, P.K.; Durbach, S.; Coville, N.J. Synthesis of Multi-Walled Carbon Nanotubes from Plastic Waste Using a Stainless-Steel CVD Reactor as Catalyst. Nanomaterials 2017, 7, 284. [CrossRef]

21. Li, Z.; Yu, X.; Liang, Y.; Wu, S. Carbon Nanomaterials for Enhancing the Thermal, Physical and Rheological Properties of Asphalt Binders. Materials 2021, 14, 2585. [CrossRef]

22. Wang, J.; Shen, B.; Lan, M.; Kang, D.; Wu, C. Carbon nanotubes (CNTs) production from catalytic pyrolysis of waste plastics: The influence of catalyst and reaction pressure. Catal. Today 2020, 351, 50-57. [CrossRef]

23. Yang, Y.; Wang, R.; Ding, L.; Qu, D.; Zhang, Y.; Han, Q.; Liu, N.; Piao, Y. Catalytic performance and mechanism of biochars for dechlorination of tetrachloroethylene in sulfide aqueous solution. Appl. Catal. B 2020, 278, 119285. [CrossRef]

24. Melchionna, M.; Beltram, A.; Stopin, A.; Montini, T.; Lodge, R.W.; Khlobystov, A.N.; Bonifazi, D.; Prato, M.; Fornasiero, P. Magnetic shepherding of nanocatalysts through hierarchically-assembled Fe-filled CNTs hybrids. Appl. Catal. B 2018, 227, 356-365. [CrossRef] 
25. De Luca, P.; Siciliano, C.; Macario, A.; Nagy, J.B. The Role of Carbon Nanotube Pretreatments in the Adsorption of Benzoic Acid. Materials 2021, 14, 2118. [CrossRef]

26. Jia, Z.; Kou, K.; Qin, M.; Wu, H.; Puleo, F.; Liotta, F.L. Controllable and Large-Scale Synthesis of Carbon Nanostructures: A Review on Bamboo-Like Nanotubes. Catalysts 2017, 7, 256. [CrossRef]

27. Bezerra, M.A.; Santelli, R.E.; Oliveira, E.P.; Villar, L.S.; Escaleira, L.A. Response surface methodology (RSM) as a tool for optimization in analytical chemistry. Talanta 2008, 76, 965-977. [CrossRef]

28. Vivekchand, S.R.C.; Govindaraj, A.; Seikh, M.M.; Rao, C.N.R. New Method of Purification of Carbon Nanotubes Based on Hydrogen Treatment. J. Phys. Chem. B 2004, 108, 6935-6937. [CrossRef]

29. Naseh, M.V.; Khodadadi, A.A.; Mortazavi, Y.; Sahraei, O.A.; Pourfayaz, F.; Mosadegh, S. Functionalization of carbon nanotubes using nitric acid oxidation and DBD plasma. World Acad. Sci. Eng. Technol. 2009, 49, 177-179.

30. Anjum, M.; Miandad, R.; Waqas, M.; Gehany, F.; Barakat, M.A. Remediation of wastewater using various nano-materials. Arab. J. Chem. 2019, 12, 4897-4919. [CrossRef]

31. Zhang, C.; Gong, Y.; Liu, H.; Jin, C.; Guo, H.; He, J. An efficient Co-WN/CNTs composite catalyst with multiple active sites for oxygen reduction reaction activity. Chem. Phys. Lett. 2021, 770, 138452. [CrossRef]

32. Modekwe, H.U.; Mamo, M.; Moothi, K.; Daramola, M.O. Synthesis of bimetallic NiMo/MgO catalyst for catalytic conversion of waste plastics (polypropylene) to carbon nanotubes (CNTs) via chemical vapour deposition method. Mater. Today Proc. 2021, 38, 549-552. [CrossRef]

33. Memon, I.N.; Kumbhar, M.I.; Noonari, S. Economics of Poultry Waste Use as a Fertilizer in Sindh Pakistan. J. Fish. Livest Prod. 2016, 4, 1-9. [CrossRef]

34. Bajad, G.S.; Tiwari, S.K.; Vijayakumar, R.P. Synthesis and characterization of CNTs using polypropylene waste as precursor. Mater Sci. Eng. B 2015, 194, 68-77. [CrossRef]

35. Şahan, T.; Öztürk, D. Investigation of $\mathrm{Pb}(\mathrm{II})$ adsorption onto pumice samples: Application of optimization method based on fractional factorial design and response surface methodology. Clean Technol. Environ. Policy 2014, 16, 819-831. [CrossRef]

36. Arena, U.; Mastellone, M.L.; Perugini, F. The environmental performance of alternative solid waste management options: A life cycle assessment study. Chem. Eng. J. 2003, 96, 207-222. [CrossRef]

37. Silva-Rodrigo, R.; Hernández-López, F.; Martinez-Juarez, K.; Castillo-Mares, A.; Melo Banda, J.A.; Olivas-Sarabia, A.; Ancheyta, J.; Rana, M.S. Synthesis, characterization and catalytic properties of NiMo/Al2O3-MCM-41 catalyst for dibenzothiophene hydrodesulfurization. Catal. Today 2008, 130, 309-319. [CrossRef]

38. Stamatin, I.; Morozan, A.; Dumitru, A.; Ciupina, V.; Prodan, G.; Niewolski, J.; Figiel, H. The synthesis of multi-walled carbon nanotubes (MWNTs) by catalytic pyrolysis of the phenol-formaldehyde resins. Physica E 2007, 37, 44-48. [CrossRef]

39. Das, R.; Abd Hamid, S.B.; Ali, M.; Ramakrishna, S.; Yongzhi, W. Carbon Nanotubes Characterization by X-ray Powder DiffractionA Review. Curr. Nanosci. 2015, 11, 23-35. [CrossRef]

40. Saad, N.A.; Ramya, E.; Saikiran, V.; Naraharisetty, S.R.G.; Narayana Rao, D. Novel synthesis and study of nonlinear absorption and surface-enhanced Raman scattering of carbon nanotubes decorated with silver nanoparticles. Chem. Phys. 2020, $533,110703$. [CrossRef]

41. Safarova, K.; Dvorak, A.; Kubinek, R.; Vujtek, M.; Rek, A. Usage of AFM, SEM and TEM for the research of carbon nanotubes. In Modern Research and Educational Topics in Microscopy; Méndez-Vilas, A., Díaz, J., Eds.; Formatex: Badajoz, Spain, 2007; Volume 1, pp. 513-519. Available online: http:// citeseerx.ist.psu.edu/viewdoc/download?doi=10.1.1.618.9072\&rep=rep1\&type=pdf (accessed on 6 September 2021).

42. Burakov, A.E.; Burakova, I.V.; Galunin, E.V.; Kucherova, A.E. New Carbon Nanomaterials for Water Purification from Heavy Metals. In Handbook of Ecomaterials; Martínez, L.M.T., Kharissova, O.V., Kharisov, B.I., Eds.; Springer International Publishing: Cham, Switzerland, 2019; pp. 1-20. [CrossRef]

43. Jiang, W.; Pelaez, M.; Dionysiou, D.D.; Entezari, M.H.; Tsoutsou, D.; O'Shea, K. Chromium(VI) removal by maghemite nanoparticles. Chem. Eng. J. 2013, 222, 527-533. [CrossRef]

44. Li, Z.; Bowman, R.S. Retention of inorganic oxyanions by organo-kaolinite. Water Res. 2001, 35, 3771-3776. [CrossRef]

45. Padmavathy, K.S.; Madhu, G.; Haseena, P.V. A study on Effects of pH, Adsorbent Dosage, Time, Initial Concentration and Adsorption Isotherm Study for the Removal of Hexavalent Chromium (Cr (VI)) from Wastewater by Magnetite Nanoparticles. Procedia Eng. 2016, 24, 585-594. [CrossRef]

46. Li, Y.H.; Zhao, Y.M.; Hu, W.B.; Ahmad, I.; Zhu, Y.Q.; Peng, X.J.; Luan, Z.K. Carbon nanotubes-The promising adsorbent in wastewater treatment. J. Phys. Conf. Ser. 2007, 61, 698-702. [CrossRef] 